University of Louisville

ThinkIR: The University of Louisville's Institutional Repository

\title{
The relationship between financial empowerment and health related quality of life in Family Scholar House participants.
}

Chelsey Erbaugh Franz

University of Louisville

Follow this and additional works at: https://ir.library.louisville.edu/etd

Part of the Public Health Commons

\section{Recommended Citation}

Franz, Chelsey Erbaugh, "The relationship between financial empowerment and health related quality of life in Family Scholar House participants." (2015). Electronic Theses and Dissertations. Paper 2029.

https://doi.org/10.18297/etd/2029

This Doctoral Dissertation is brought to you for free and open access by ThinkIR: The University of Louisville's Institutional Repository. It has been accepted for inclusion in Electronic Theses and Dissertations by an authorized administrator of ThinkIR: The University of Louisville's Institutional Repository. This title appears here courtesy of the author, who has retained all other copyrights. For more information, please contact thinkir@louisville.edu. 
THE RELATIONSHIP BETWEEN FINANCIAL EMPOWERMENT AND HEALTH RELATED QUALITY OF LIFE IN FAMILY SCHOLAR HOUSE PARTICIPANTS

By

\author{
Chelsey Erbaugh Franz \\ B.S. Western Oregon University, 1997 \\ M.S. Oregon State University, 2004 \\ A dissertation \\ Submitted to the Faculty of the \\ School of Public Health and Information Sciences of the University of Louisville \\ in Partial Fulfillment of the Requirements \\ for the Degree of \\ Doctor of Philosophy in Public Health Sciences \\ Department of Public Health and Health Promotion \\ University of Louisville \\ Louisville, Kentucky
}

May 2015 

THE RELATIONSHIP BETWEEN FINANCIAL EMPOWERMENT AND HEALTH RELATED एس山س山سmسmسQUALITY OF LIFE IN FAMILY SCHOLAR HOUSE PARTICIPANTS

By

Chelsey Erbaugh Franz

B.S. Western Oregon University, 1997

M.S. Oregon State University, 2004

A Dissertation Approved on

March 31, 2015

By the following Dissertation Committee

Dissertation Chair

Monica Wendel, DrPH, MPH

Richard Wilson, DHSc

Kathleen Cooter, PhD.

Pavel Zahorik, PhD. 


\section{DEDICATION}

This dissertation is dedicated to my daughters

\section{Addison Ryn Erbaugh Franz}

and

\section{Gwyneth Reese Erbaugh Franz}

who are tangible evidence of, and daily motivation to work towards, God's purpose and plan for my life. 


\section{ACKNOWLEDGEMENTS}

“...from everyone to whom much is given, much shall be required..." (Luke 12:48). I praise God for the opportunities He has given and look forward to fulfilling my requirements. I would also like to thank my husband, Eddie, who God placed in my life, for unwavering love and support on this journey. He is a daily source of strength, humor and stability. I am blessed to be his wife.

I would like to thank my committee chair, Dr. Wendel, for her guidance on this study and willingness to keep my timeline. I would also like to thank my individual committee members, Dr. Wilson, Dr. Zahorik and Dr. Cooter, for their efforts and expertise given in the completion of this document. A special thank you to Dr. Cooter, who consistently championed not only me, but her many other students, helping us to believe we can make a difference. I am blessed to have each of you serve on this final step towards my doctorate degree.

I would like to thank Family Scholar House and their participants for the time and feedback provided for this study. A special thank you to Jocelyn Fetalver for her willingness to assist in any way asked. I am blessed to have had an opportunity to learn from people and an organization that work to alleviate poverty, filling a desperate need in our society.

Finally, I would like to thank my parents for leading by example and instilling in me an understanding that higher education is not a choice for our family, but an expectation. This understanding will be passed on to my own children and to any grandchildren that will follow. I am blessed to be a part of this family. 


\section{ABSTRACT \\ प \\ THE RELATIONSHIP BETWEEN FINANCIAL EMPOWERMENT AND HEALTH RELATED QUALITY OF LIFE IN FAMILY SCHOLAR HOUSE PARTICIPANTS

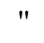 \\ Chelsey Erbaugh Franz \\ March 31, 2015}

The Family Scholar House program was a unique intervention designed to stop the cycle of poverty by providing college education and support to single parents. The different aspects of the Family Scholar House program addressed each of the five social determinants of health (economic stability, education, social and community context, health care, and neighborhood and built environment). Results of the studies showed that participant's mental health and general health rating, as measured by a healthrelated quality of life survey, improved during the time in the Family Scholar House program. Upon graduation from the program, the mental health and the health rating of the Family Scholar House participant's was no longer significantly different from a comparison population. Qualitative results indicated that this improvement might be related to the decrease in stress due to the network of support provided to the Family Scholar House participants. Thus, the study provides evidence that participation in the Family Scholar House program may improve components of health-related quality of life. 
TABLE OF CONTENTS

PAGE

AKNOWLEDGEMENTS

iii

ABSTRACT

CHAPTER 1: INTRODUCTION

CHAPTER 2: LITERATURE REVIEW

CHAPTER 3: METHODS

CHAPTER 4: RESULTS

Quantitative

Qualitative

45

Summary of findings

58

CHAPTER 5: DISCUSSION

SUMMARY AND CONCLUSIONS

65

REFERENCES

69

CURRICULUM VITA

76 


\section{CHAPTER 1: INTRODUCTION}

Many factors affect individual and population health. In an effort to better prioritize, benchmark, and monitor progress in improving health, in 1979, the U.S. Department of Health and Human Services (DHHS) developed the Healthy People program. The Healthy People program convenes content experts from around the country to identify issue topics of most concern across the population and to develop 10year goals and objectives related to those topics. The most recent set of 10-year goals and objectives are documented in Healthy People 2020. These goals and objectives, created in 2010 as a follow up to Healthy People 2010 is a "10-year agenda for improving the Nation's health." For the first time, Healthy People 2020 lists social determinants of health $(\mathrm{SDOH})$ as a topic with a goal to "create social and physical environments that promote good health for all"(Centers for Disease Control and Prevention, 2014a). The SDOH include a variety of factors that affect health including economic stability, education, social and community context, health care, and neighborhood and built environment. Persistent poverty and low socioeconomic status (SES) are linked to poor health outcomes. Interventions designed to improve health for individuals and populations need to consider financial stability, and thus the impact of poverty and low SES, and its role in health-related outcomes.

\section{Social Determinants of Health}

According to the World Health Organization (WHO) the definition of health is "a state of complete physical, mental and social well-being and not just the absence of sickness or frailty" (WHO, 1946). Within a person's overall health status, multiple determinants, or circumstances, exist which affect the mental, social, and physical state of health. These circumstances, termed social determinants of health (SDOH), include "the circumstances in which people are born, grow up, live, work and age, and the systems put in place to deal with illness" (World Health Organization, 2008). The Centers for Disease

Control and Prevention (CDC) discuss the SDOH, noting specifically economic stability, education, social and community context, health care, and neighborhood and built environment as the five determinants within the SDOH that affect a person's overall state of health. Clean, accessible water, access to trained 
medical providers, family support for healthy living, and educational opportunities are among several variables that are included in both the WHO definition of health as well as the CDC's five determinants of health (U.S. Department of Health \& Human Services, 2014b). For example, a child born in Haiti has a greater chance of dying in infancy than a child born in the U.S. (Barros et al., 2012) because poor education and infrastructure, subsequent poor maternal health, and lack of access to medical care greatly affect the child's survival. These determinants produce dramatic disparities in health risk, access to services, and outcomes in and across populations.

Data have long demonstrated the relationship between economic stability and a person's physical, mental, and social health. Research indicates that several financial variables (income, liquid assets, home ownership, saving accounts, etc.) relate to overall health (Miller, Vigdor \& Manning, 2004). Populations in poverty and populations who are uninsured or underinsured (due to lack of financial ability to purchase health insurance) have worse mental and physical health outcomes (Adler et al., 1994; Backlund et al., 2007; de Castro, Gee, \& Takeuchi, 2010; Gallo \& Matthews, 2003; Gornick, 2002; Kim \& Richardson, 2012; Levine Coley \& McPherran Lombardi, 2014; J. W. Lynch, DaveySmith, Harper, \& Hillemeier, 2004; J. W. Lynch, Harper, Kaplan, \& DaveySmith, 2005; J. W. Lynch, Smith, Kaplan, \& House, 2000; Myers, 2009; Nobles, Ritterman Weintraub, \& Adler, 2013; Rhine \& Greene, 2006; Rothwell \& Han, 2010; Sanmartin et al., 2003; Sweet, Nandi, Adam, \& McDade, 2013; S. B. Thomas \& Quinn, 2008; Wang, 2002; Wilson, 2009). Health outcomes are affected by the SDOH, and the SDOH are, in turn, affected by economics, social policies, and politics (World Health Organization, 2008).

\section{Poverty}

According to the U.S. Census Bureau estimates for 2012, 46.5 million people in the United States ( $15 \%$ of the population) live in poverty. This estimate may be low, given the underrepresentation of certain populations in Census estimates, such as the homeless population and people in the prison system (United States Census Bureau, 2012), both known to have a disproportionately greater poverty rate. The federal poverty level (FPL) set by DHHS in 2012 for a family of four was an annual household income of $\$ 23,050$ (U.S. Department of Health \& Human Services, 2014a). Across the U.S., New Hampshire had the lowest state poverty rate of 5.6 percent, and Mississippi had the highest state poverty rate at 17.4 percent (United States Census Bureau, 2012). Kentucky ranked $44^{\text {th }}$ in the nation; 19.4 percent of Kentucky's population 
lived below the FPL in 2012. In the Louisville Metro area, nearly one-third of households lived on less than \$25,000 per year (Nesbitt, Harris, Hall, \& Pallam, 2012). Further, 10.5 percent of Louisville families, 31.3 percent of single, divorced and separated women in Louisville, and 16.8 percent of all Louisville families with children live below the FPL (S. Thomas, 2012). Compared to other developed countries, national and local poverty rates are high (Gould \& Wething, 2012).

\section{Socioeconomic Status}

Living in poverty affects an individual's ability to achieve financial stability and ultimately good health. Poverty can be defined in a multitude of ways, including lack of access to food, water, clothing, shelter, education and income. Poverty is also a component of socioeconomic status (SES), which includes income, occupation, place of residence, and education (Farlex, 2014). Lower SES relates to poor economic health which, in turn, affects the overall state of health and well-being of everyone from the individual to the larger population (Centers for Disease Control and Prevention, 2010, 2014a). Multiple studies attest to the relationship between low SES and poor health (Adler et al., 1994; Backlund et al., 2007; Centers for Disease Control and Prevention, 2010, 2014a; Gallo \& Matthews, 2003; Gornick, 2002; J. W. Lynch et al., 2004; J. W. Lynch et al., 2005; J. W. Lynch et al., 2000; Myers, 2009; Nesbitt et al., 2012; Nobles et al., 2013; Rhine \& Greene, 2006; Rothwell \& Han, 2010; Sanmartin et al., 2003; S. B. Thomas \& Quinn, 2008; Wang, 2002; Wilson, 2009). More recently, an article in the NY Times (2014) tracked life expectancies in two U.S. counties separated by 350 miles and a dramatic difference in SES. The authors noted that, “...residents of Fairfax County (VA) are among the longest-lived in the country: Men have an average life

expectancy of 82 years and women, 85, about the same as in Sweden. In McDowell (WV), the averages are 64 and 73, about the same as in Iraq" (Lowery, 2014).

Dating from 1967 to 2000, Gallo \& Matthews cite eight literature reviews on SES and health which indicate an inverse relationship between SES and morbidity and mortality (Gallo \& Matthews, 2003). These studies identified both individual and community SES as predictors of poor health, as well as examined multiple health outcomes ranging from all causes of mortality to more specific outcomes, such as infant mortality, diabetes, and cancer.

A 2009 literature review confirmed the same conclusions (Myers, 2009). SES plays a contributing role in increased health disparities, negative health behaviors and negative health outcomes (morbidity and 
mortality), among other outcomes. Thomas \& Quinn (2008) supported these findings, also noting the role of race and ethnicity in poverty and health status.

\section{Health-Related Quality of Life}

Traditionally, researchers measured health via morbidity and mortality outcomes. More recently, quality of life has gained attention when examining overall health outcomes. Consistent with the more holistic WHO definition of heath, quality of life takes into consideration factors such as jobs, housing, schools, neighborhoods, cultures, values, and spirituality. Thus, health-related quality of life (HRQoL) includes SES, social support, health risks, health conditions, and functional health status. Because HRQoL considers multiple levels and determinants of heath rather than just one aspect, outcomes considering quality of life are more complex and provide much richer feedback in the measurement of health (Centers for Disease Control and Prevention, 2000). Thus, HRQoL tools are useful in identifying poor health in specific populations and geographical areas, and knowledge gained from these tools should drive interventions and policies to improve health outcomes (Centers for Disease Control and Prevention, 2000).

\section{Interventions to Improve Financial Stability}

In the U.S., the federal government is tasked with alleviating poverty by providing resources for families and individuals living in lower SES categories. Focus areas include food assistance, housing assistance, job training, income assistance, and tax breaks (The White House, 2014). Within each of these focus areas, a variety of local governmental programs and non-profit agencies exist to work with families and individuals with mid- to low-incomes with the overarching goal of providing temporary assistance for immediate needs. Some examples include assistance with rent or utilities, and food and nutritional supplements. While these services provide a short-term solution, they can also promote reliance on government assistance and the goal of financial self-sufficiency is not advanced (City of Louisville, 2014).

Traditionally, poverty alleviating resources focus little on financial education and empowerment among the poor; indeed, many of the services are provided by social service providers who have little to no training regarding financial education and empowerment for themselves or their clients (Sherraden, Laux, \& Kaufman, 2007). More recently, however, organizations and social service providers are attempting to integrate financial empowerment (FE) into the resources provided to low-income populations in an effort to reduce reliance on government assistance, improve self-sufficiency, and alleviate poverty (City of 
Louisville, 2014; Lentz, 2013; NYC Department of Consumer Affairs Office of Financial Empowerment, 2013; SF Office of Financial Empowerment, 2014; Sherraden et al., 2007).

An example of financial empowerment integration into social services provided to the area's midto-low income population is Louisville Metro Government's Department of Community Services and Revitalization (CSR). Within CSR, individuals and families in the greater Louisville area are offered resources designed to provide temporary assistance to those challenged by financial instability. CSR, however, recognizes the need to provide more than just symptomatic relief and thus, in 2012, joined the Cities for Financial Empowerment (CFE) Coalition. Currently, the coalition consists of 12 member cities nationwide committed to providing financial empowerment to the people being served in an effort to create financial stability among the nation's mid- to low-income population (City of Louisville, 2014). While the implementation of FE varies from city to city, the primary aim of improved financial health remains the same.

\section{Family Scholar House}

Locally in Louisville, CSR works with the Family Scholar House (FSH) program which implements FE into curriculum provided to single-parent college student clients (Family Scholar House, 2014). The mission of FSH is "to end the cycle of poverty and transform our community by empowering families and youth to succeed in education and achieve life-long self-sufficiency.” Established in 1995 as Project Women, the organization was formed by a group of nuns from seven orders who came together to help provide a way for single mothers to break the cycle of poverty. Initially providing housing and educational assistance to one single mother, the program has grown considerably over the past 20 years and now serves several families each year.

Though some students earn an Associate's degree or vocational certification, the intent of the program is to assist clients with achieving a Bachelor's degree. With this degree and the education, support, and empowerment provided by FSH, the participants hope to secure self-sufficiency and reduce reliance on public assistance. Since the program began, 347 families, with a total of 528 children, have lived in the FSH residential program. The participants have completed 93 percent of the college credits attempted, and 75 percent have exited the program to stable employment. In addition, 100 percent of the participants 
exited the FSH program into stable housing, a key factor of success, considering 100 percent of the participants entered the program homeless or with unstable housing (Family Scholar House, 2014).

Participant qualifications include single men and women who: "have a child, children, or are pregnant, meet low-income housing requirements, have a high school diploma or GED, have the desire to pursue a college degree." In order to receive housing, participants must apply for housing and take four financial success classes and four academic success classes offered at the FSH campuses. These classes are offered weekly, such that the qualifications can be met within a two-month time frame. By attending these classes, applicants earn points. When an apartment becomes available, the applicant with the most points is offered the residence. Though the financial and academic success classes are required to apply for housing, the participants can also earn points, and thus improve their chances of housing, by attending other FSH classes and workshops and case management appointments. In addition, residents must also be full-time students with a 2.0 or higher grade point average (GPA), attend monthly meetings, volunteer four community service hours, and save $\$ 10$ per month. The monthly meetings are held with family service advocates who provide guidance, coaching, and counseling (Family Scholar House, 2014).

The Family Scholar House curriculum consists of housing support, educational support, family nutrition and wellness, and financial success. To provide housing support, FSH has four campuses in the Louisville area. In 2008, the Louisville Scholar House was opened, with 56 apartments. In 2011, the Downtown Scholar House opened, providing 54 apartments. The Stoddard Johnston Scholar House opened in 2013, with 57 apartments, and the Parkland Scholar House was opened in 2013, adding another 48 apartments. To ensure housing selection is unbiased, FSH works with Winterwood Property Management, which maintains Housing and Urban Development (HUD) standards for every applicant. Thus, participants who are offered housing within a FSH campus are required to put 30 percent of their income toward rent, in compliance with the Section 8 housing subsidy vouchers. Each of the Family Scholar House campuses include common areas that house an Academic Services Center (computers, printers, internet access, etc.) as well as kitchens, meeting rooms, and case management and staffing offices. Residents have access to housing until they earn their degree. Following graduation, the residents have three months to transition to other housing. To date, 14 FSH participants have purchased their own homes upon leaving the Scholar House residence (Family Scholar House, 2014). 
Along with housing, educational support for FSH participants is provided through academic advisors that assist with securing grants, scholarships, and financial assistance for college courses. Participants are required to enroll full-time in an accredited college or university, focusing on pursuit of a post-secondary degree that is in line with their career goals, and maintain a 2.0 or higher grade point average. In addition, in order to promote early childhood education, residential parents have access, depending on availability, to University of Louisville's early childhood learning facilities. To date, 176 college degrees have been earned by FSH participants, and 23 children of Scholar House participants are also pursuing a post-secondary education. (Family Scholar House, 2014).

Family Scholar House also provides family nutrition and wellness programs. These consist of a variety of health and nutrition workshops and health fairs including cooking and exercise classes designed for adults and children. Once each month, a University of Louisville clinician visits the campus to offer informational courses on general health and wellness. At pre-placement, case managers take a health history for the participants and the children, connecting them with local resources for needed medical assistance (Family Scholar House, 2014).

Finally, FSH offers a financial success curriculum. This consists of four financial success workshops with the objectives to "identify financial habits, gain an awareness of money management and its effects on relationships, modify financial behaviors, and become life-long learners". Currently, Session 1 of the FSH financial success program includes money habits, goal setting, and a cash flow analysis. Session 2 adds information regarding budgeting and prioritization of income. Session 3 introduces different types of income, credit, credit history, credit scores and debt. The final session, Session 4, includes banking information and resources, asset building and identity protection. Once participants complete these four workshops, long-term guidance and counseling is provided by an FSH family service advocate who has also been trained in the financial empowerment concepts (Family Scholar House, 2014).

The current financial success curriculum utilized by FSH is modeled after a program that was created by the National Center for Family Literacy (NCFL) and the National Endowment for Financial Education (NEFE) (Waddell, 2015). This financial literacy curriculum, titled Financial Opportunity Family Progress (FOFP), was developed and piloted in 2008 with undergraduate students at Spalding University. The program consisted of a 6-week course followed by 4 to 6 months of continued financial coaching and 
guidance. Though a formal evaluation was not performed on the program until 2011, NEFE and NCFL noted an improvement in pre/post testing of financial literacy. As such, Women 4 Women (a non-profit organization that secures funding for local programs that empower women) partnered with NCFL to continue the program and by 2009 , the program was implemented at multiple sites throughout Louisville. In 2013, Women 4 Women turned the financial program over to FSH with the agreement that Scholar House would continue to provide financial education to the local community (Cruse, 2015; Waddell, 2015).

With the combination of these multiple components of the program, the Family Scholar serves as a local intervention to alleviate poverty, raise SES, and improve health by targeting multiple intersecting areas of social determinants of health. In addition, the program is unique from other local interventions because of the intentional implementation of financial empowerment among the case managers and social workers who provide guidance, training, and counseling to the FSH participants.

\section{Research Questions}

Multiple studies indicate social determinants of health, including poverty and SES, affect HRQoL, and a significant number of research studies have been done considering why poverty exists. Yet research is lacking in understanding best practices to address the impact these factors have on HRQoL. If a program, such as Family Scholar House, is able to specifically address and alleviate the impact of poor or lack of housing, education, income, and community support, then a measurable outcome should be improved

HRQoL. Additionally, financial empowerment is a new field in the social and behavioral sciences; there are few studies done on financial empowerment and HRQoL. Understanding the effect of financial empowerment on HRQoL is important in driving the design and implementation of future and existing interventions. Thus, the purpose of this study is to examine the effect financial empowerment can have in a person's HRQoL. Because Family Scholar House addresses multiple areas of poverty, SES, and social determinants of health (all noted to impact health), the current study seeks to answer three important research questions:

1. To what extent is participation in the Family Scholar House (FSH) program related to healthrelated quality of life (HRQoL) for single mothers?

2. To what extent is HRQoL related to the amount of time a single mother has been in the FSH program? 
3. What relationship does financial empowerment (FE) have with HRQoL for FSH participants?

The researcher hypothesizes that participation in the Scholar House program is related in an improved HRQoL and that the longer a participant is in the Scholar House program, the more improvement in HRQoL is noted. In addition, the researcher hypothesizes that financial empowerment positively affects HRQoL and that those who are provided financial empowerment will have an improved HRQoL. This study aims to provide insight into the role of FE among FSH participants and the relationship to HRQoL.

This study has been approved by the University of Louisville's Institutional Review Board to use human research subjects (14.1117).

\section{Definitions}

Behavioral Risk Factor Surveillance System (BRFSS): the world's largest telephone survey, utilized to determine prevalence of population health risk behaviors (Centers for Disease Control and Prevention, 2014b)

Economic stability: also termed financial stability; the ability to absorb financial losses (Schinasi, 2004)

Financial Empowerment (FE): also termed financial education and financial literacy; provides individuals the education, skills, opportunity and resources to be responsible and accountable for their financial health (Cruse, 2015; Lentz, 2015; Waddell, 2015)

Family Scholar House (FSH): also termed Scholar House; A Louisville-based, non-profit organization that provides stable housing to single parents working towards a 4-year college degree (Family Scholar House, 2014)

Health Related Quality of Life (HRQoL): includes SES, social support, health risks, health conditions and functional health status; considers multiple levels and determinants of heath; more complex and provides much richer feedback in the measurement of health (Centers for Disease Control and Prevention, 2000)

Poverty: includes lack of access to food, water, clothing, shelter, education and income (Farlex, 2014) Social Determinants Of Health (SDOH): includes, "the circumstances in which people are born, grow up, live, work and age, and the systems put in place to deal with illness" (World Health Organization, 2008); specifically economic stability, education, social and community context, health and health care, and neighborhood and built environment(Centers for Disease Control and Prevention, 2014c) 
Socio-Economic Status (SES): includes income, occupation, place of residence, and education (Farlex, 2014) 


\section{CHAPTER 2: LITERATURE REVIEW}

\section{Introduction}

Resources, access, and opportunities affect health. Information on early childhood education (resource), a high quality neighborhood school (access), and after school programs focused on reading, math and science (opportunity) are examples of factors that are afforded to some members of society, but not to all. These factors affect individual and population health. When examining these factors and the role they play in health outcomes, researchers have conducted studies on the disparities related to these specific factors. However, only within the last decade has an effort been made to collaborate among professionals from multiple disciplines to design and examine interventions through a lens that considers the complexity of the social determinants of health and the social factors that influence health. Utilizing an interdisciplinary approach, this chapter will lay the foundation for the role financial stability has in HRQoL among people in the low SES category through a review of the existing literature. The literature review outline presented by Goldschmidt (1986) dictated the methodology of this Chapter 2, including the articles, reviews and meta-analyses chosen, validated, organized and presented in this review (Goldschmidt, 1986).

This literature review utilized several databases. These included PubMed, EBSCO host, ProQuest, Google Scholar, and Project MUSE. Key terms in these searches included "financial empowerment," "financial education," "financial literacy," "self-determination," "self-sufficiency," "health outcomes," "quality of life," and combinations of these terms. At times, the terms "meta-analysis" and "systematic review" were included in the refined search boxes. The presence of empirical evidence, validated methodology, and a multi-source reference section dictated the selection of articles chosen for the literature review.

\section{Social Determinants of Health}

To better understand the variables that affect health, consideration must be given to the social determinants of health which include "the circumstances in which people are born, grow up, live, work and age, and the systems put in place to deal with illness" (World Health Organization, 2008). To be more 
specific, the CDC describes SDOH as economic stability, education, social and community context, health and health care, and neighborhood and built environment. These five determinants affect a person's overall state of health in a variety of different, and often intersecting, ways (U.S. Department of Health \& Human Services, 2014b). For example, statistics show that in the U.S., individuals in lower SES categories live in neighborhoods with higher crime rates (neighborhood and built environment) and are provided a sub-par schooling (education). These components lead to a life-trajectory commonly ending in either the prison system (social and community context) or a lower paying job (economic stability). The combination of these determinants ultimately creates poor health (Guggenheim, 2010). Holistic improvement of health outcomes must attend to the differing SDOH.

\section{Socioeconomic Status (SES)}

Socioeconomic status includes components of income, occupation, education, and place of residence. These components intersect with SDOH and are shown to affect health (Adler et al., 1994; Backlund et al., 2007; Centers for Disease Control and Prevention, 2010, 2014a; Gallo \& Matthews, 2003; Gornick, 2002; J. W. Lynch et al., 2004; J. W. Lynch et al., 2005; J. W. Lynch et al., 2000; Myers, 2009; Nesbitt et al., 2012; Nobles et al., 2013; Rhine \& Greene, 2006; Rothwell \& Han, 2010; Sanmartin et al., 2003; S. B. Thomas \& Quinn, 2008; Wang, 2002; Wilson, 2009). The most commonly cited systematic review on SES and health, by Alder et al., indicated a graded association of health at all levels of SES. The authors chose to utilize a grade of membership (GOM) analysis to examine the different variables associated with SES and health. Use of the GOM allowed the authors to examine multiple variables with increasing model stability (rather than decreasing stability as seen with regression). These included psychological effects (hostility, depression), social ordering effects (one's position in the SES hierarchy), and health behaviors (alcohol, smoking, physical activity). The authors found that as one's SES improves, so does one's health; as one's SES declines, so does one's health (Adler et al., 1994).

Backlund and colleagues supported these findings, noting the health of individuals, families, and populations are affected by their SES; results indicated a direct relationship between SES and health (Backlund, Sorlie, \& Johnson, 1996). Backlund et al. utilized a long-term prospective study to examine the role of SES and mortality. Looking at 14 samples of population data taken by the US Census Bureau, the authors tracked over 500,000 respondents for a range of 2.75-8.75 years, noting over 40,000 deaths. The 
authors used a Cox proportional hazards model to examine the relationship between SES and mortality, finding that in the 25-64 ages range (considered the working years) and the over 65 age range (considered the elderly), the income-mortality gradient (the slope describing an inverse relationship with income and mortality) was larger for those in the lower SES group. This gradient increased further for women in extreme poverty compared to women in low-to-mid poverty (Backlund et al., 1996). Both studies indicate a direct association between SES and health outcomes.

Researchers also examined the role of SES, health, and indirect associations between the two. Gallo and Matthews (2003) examined the role of low SES, negative emotions and cognitions, and health related outcomes providing evidence for an association between low SES and hostility, hopelessness, anxiety, and depression (Gallo \& Matthews, 2003). Specifically, the authors focused on cardiovascular diseases and all-cause mortality, due to the ample amount of literature on these areas. After summarizing the current findings on the direct relationship between SES and morality, the authors looked at the indirect association between SES and health, citing articles that addressed SES, physical outcomes, and an emotional/cognitive variable simultaneously. The researchers conceptualized SES as access to resources, measured as assets, which included income, wealth, and educational attainment. The authors examined measurements of hostility, hopelessness, anxiety, and depression, which may indirectly affect health, noting an increase in these measurements among low SES individuals.

Myers supported these indirect associations, examining the role of SES concerning exposure to stress, racism, and discrimination and the effect on health. Results indicated greater morbidity and mortality suffered by low SES, indicating the role of ethnicity and the stress associated with one's ethnic group, as a contributor to these poor health outcomes (Myers, 2009). Myers chose the African American (AA) ethnic group as the focus for examination of multiple health outcomes including heart disease, diabetes, HIV/AIDS, infant mortality, and health care access because epidemiological data indicates the AA populations suffers greater morbidity and mortality than other ethnicities (United States Census Bureau, 2012). Findings from the above studies and systematic reviews indicate that SES both directly and indirectly affects individual and population health. Those in the lower SES category suffer worse health than those in higher SES categories.

\section{Income Inequality}


A complementary way to examine the role of SES in health is to consider income inequality (J. W. Lynch et al., 2004; J. W. Lynch et al., 2005; J. W. Lynch et al., 2004; J. W. Lynch et al., 2000; Pickett \& Wilkinson, 2007, 2015; Richard G. Wilkinson \& Pickett, 2006). Most current, a 2015 literature review found evidence to support a causal relationship between income inequality and poor health outcomes (Pickett \& Wilkinson, 2015). The authors utilized an epidemiological causal framework that considers evidence as a whole, rather than identifying individual study findings, to determine if exposure (income inequality) caused an outcome (poor health and well-being). Within this framework, biological plausibility, including temporality and consistency, and lack of alternative solutions were considered. The criteria of biological plausibility was supported through hundreds of analyses, considering millions of cases, that covered cohort, time-series and cross-sectional designs. These studies were done on a variety of populations over multiple times. The authors found that $94 \%$ of these studies showed at least one association between income inequality and poor health, citing "overwhelming evidence that greater inequality is linked to worse health and more violence". Furthermore, the authors used multiple studies that supported the role of chronic stress and poor health outcomes to demonstrate the effect of income inequality on health. Examining the evidence as whole, the authors found that the "body of evidence on income inequality and health points strongly to a causal connection" (Pickett \& Wilkinson, 2015).

Wilkinson and Pickett built the above theory on several previous studies that found that higher inequality relates to poorer population health (J. W. Lynch et al., 2004; J. W. Lynch et al., 2005; J. W. Lynch et al., 2000; Pickett \& Wilkinson, 2007; R.G. Wilkinson \& Pickett, 2007; R. G. Wilkinson \& Pickett, 2008, 2009). Income inequality is a measurement of the difference, or gap, between those in a society with the most wealth compared to those within the society with the least wealth. The authors examined data on life expectancy, mental illness, obesity, homicides, imprisonment, teenage pregnancies, education, distrust and social mobility finding an association between societal struggles and income inequality. Populations with higher income gaps also had worse health and social problems.

The 2000 Lynch study combined a literature review with correlation analyses of gross domestic product (GDP) and life expectancy, mortality, and income inequality. Rather than utilizing absolute income, researchers noted the use of a psychosocial interpretation (trust, social support, respect, etc.) of the data to understand the impact of income inequality and individual health. Results indicated psychological 
functioning is associated with individual health and is affected by individual and population income inequality. Individuals who live in areas with higher income inequality suffer less optimal health overall due to the psychological affects produced by the inequality. In addition, the researchers noted the relationship between political agendas that drive income inequality and the impact of public resources on schools, health care, working conditions, and social welfare, all directly related to one's SDOH. For example, politicians concerned with lessening government involvement in education reduce funds given to K-12 schools. Those schools located in and supported by families in higher SES communities will continue to have funds to improve school resources because of the economic stability of the community; those schools located in and supported by low SES communities will not have the funds to improve school resources and thus educational opportunities for students are lacking. Less equitable distribution of an area's resources negatively impacts individual health (J. W. Lynch et al., 2000).

Lynch et al. gave further support of the relationship between income inequality and health, specifically in the U.S., indicating a link between increased income inequality and poor population health. A systematic review of 98 studies and comparisons of U.S. income inequality trends with U.S. Census Bureau 100-year national and 30-year regional age- and cause-specific mortality rates indicated that income inequality increases the effect of risk factors associated with heart disease (i.e. smoking). Weaker association were also noted for other health outcomes such as stroke and suicide (J. W. Lynch et al., 2004).

Wilkinson \& Pickett noted the similar findings, adding a specific examination of SES and noting that areas where social status is more pronounced also suffered from lower health and higher income inequality. The authors interpreted 168 analyses, noting the income inequality and poor health relationship exists more so in areas where SES is more apparent (Pickett \& Wilkinson, 2007).

\section{Health and Health Care Access}

Other researchers have examined health outcomes by exploring the role of health care and health care access among those in the lower SES categories, noting less health among those who had no or limited health care access (Baker, Sudano, Albert, Borawski, \& Dor, 2001; Dow, Schoeni, Adler, \& Stewart, 2010; Miller, Richardson Vigdor, \& Manning, 2004; The Kaiser Commission on Medicaid and the Unisured, 2014; Wilson, 2009). Wilson (2009) compared health care in the U.S. to health care in Canada and noted that in in the U.S., higher SES provided a level of protection against morbidity and mortality that was not 
provided to lower SES populations. Wilson followed the theory of fundamental causes to provide evidence that having access to multiple resources (as afforded by higher SES populations) protects a person from health risks. Populations within the lower SES categories lacked access to resources and thus, the health risks affected health outcomes to a greater degree. In line with the aforementioned theory, this discrepancy was most prominent concerning preventable diseases. Because people in higher SES categories can access resources known to prevent negative health outcomes, access lessened the health risk. People in lower SES categories, despite knowing about preventative resources, lacked access. Thus, morbidity and mortality in this population was higher (Wilson, 2009).

In addition, by comparing the U.S. to Canada, Wilson (2009) provided evidence in line with the theory of fundamental causes regarding competition for resources. The U.S. health care system is a competitive market while Canada has universal coverage for health care. Results from Wilson's study (2009) indicated a larger discrepancy between the higher and lower SES groups in the U.S. compared to the same groups in Canada. In the U.S., higher SES standing was equated with better access to health care resources and thus better health; a lower SES standing was equated with less access to health care and thus poorer health. The universal coverage offered in Canada provided a buffer, thus minimizing these effects (Wilson, 2009).

The Kaiser Commission on Medicaid and the Uninsured analyzed data from the 2013 National Health Interview Survey (NHIS) supported these findings, specifying that lack of insurance was associated with increased barriers to health care. Due to cost, respondents of the survey who lacked insurance were more likely to postpone seeking health care, more likely to go without needed care and were more likely to be unable to afford a prescription drug (The Kaiser Commission on Medicaid and the Unisured, 2014).

A report by Miller, Vigdor and Manning (2004) offered further evidence to support lack of health insurance as a contributing factor to poor health by examining the financial cost of the uninsured in the U.S. Utilizing the Institute of Medicine's (IOM) six reports on the adverse effects of being uninsured (to individuals, families, communities and society) the authors conducted a cost-analysis. The results of the analysis indicated economic costs to both individuals and societies that were associated with being uninsured. Among the uninsured, these costs included poorer health and higher mortality, exposure to financial risk (unexpected medical bills are the leading cause of bankruptcy in the U.S.) (LaMontagne, 
2014), and ineffective communicable disease control in communities. The costs of an individual being uninsured trickled out from the individual to all members of the society (Miller, Vigdor \& Manning, 2004). In addition, the authors also conducted an analysis of the cost of covering the uninsured, either privately or publicly. They noted the cost of this coverage was well below the societal gains of improved health and longer, more productive lives (Miller, Vigdor \& Manning, 2004).

With the design and implementation of the Affordable Care Act (ACA), millions of mid- to lowincome individuals are afforded health care coverage, which should improve health-related outcomes for U.S. citizens and reduce financial risk (Centers for Medicare \& Medicaid, 2014; LaMontagne, 2014). However, research on these health outcomes is just beginning, and long-term results will not be available for several years.

\section{Interventions}

While the ACA is a newer intervention, other governmental programs have been in effect for several years. The supplemental nutrition assistance program (SNAP), was implemented on a broad scale and designed to improve health outcome for U.S. citizens. This resource of the United States Department of Agriculture (USDA), formerly known as food stamps, "is the Nation's largest domestic food and nutrition assistance program for low-income Americans" (United States Department of Agriculture, 2014). With this program, eligible applicants are provided access, through an electronic benefits transfer (EBT) card, to specified food and food products. The federal government defines participant eligibility, benefits provided, and administrative rules, while the state government determines how the above is carried out. A complementary program, women, infant and children (WIC), is provided for women, infants and children under the age of 5 who are at nutritional risk (United States Department of Agriculture, 2014). Several positive health outcomes have been noted through use of the WIC program. A 2012 report by the United States Department of Agriculture (USDA) reviewed literature on the program (United States Department of Agriculture, 2012). While findings on WIC participation and infant/child overweight and obesity risks were mixed, evidence suggests that participation in the WIC program is positively associated with gestational age, mean birth weight, improved diets (higher iron intake, less sugar intake, more food variety) and with greater utilization of preventative and general health care (United States Department of Agriculture, 2012). 
The SNAP and WIC interventions are examples of broad policies that effect health outcomes in the U.S. Other interventions, including housing assistance, tax relief, job training, and income assistance are also implemented at both the state and federal levels (The White House, 2014). Brooks and Wiedrich used a ranking system to show that states with multiple and strong policies benefitting individuals and families in the low-income bracket (ie. funding for IDA's, protection from payday lenders, removal of asset limits on TANF and SNAP) have individuals and families who are better suited to handle financial crises (i.e. the 2008 recession). This may carry over into improved health (Brooks \& Wiedrich, 2012).

In the U.S., Brooks and Wiedrich (2012) examined five areas that measured asset building: financial assets \& income, business and jobs, housing and homeownership, health care, and education. Researchers utilized these areas to determine the ability of people to achieve asset building in their state of residence as a result of the state policies currently in place. Job quality was cited as area needing policy and program reform. Researchers found over $20 \%$ of jobs are considered low wage jobs, $46 \%$ of employers do not offer health insurance, and 55\% of workers do not take part in retirement planning. A second area of focus was homeownership. In 2010, $73 \%$ of white households owned a home (a buildable asset) compared to just $47 \%$ of households of color. As homes appreciate, those without this ownership miss potential asset building. Brooks and Wiedrich (2012) also examined credit scores. In the U.S., 56\% of people have poor credit scores. Strong credit allows individuals to gain access to affordable car and housing loans and to bolster job and rental applications. Poor credit increases use of high-interest loan and credit markets while limiting the ability to retain quality jobs and housings, thus further perpetuating the cycle of poverty.

Finally, the researchers discussed education as a key factor in improving financial health of individuals and communities (though citing mixed results). Despite the improvement of educational outcomes, in $2011,8^{\text {th }}$ graders still scored low with only $35 \%$ of students proficient in math and $34 \%$ proficient in reading. In addition, though more students are earning a college degree (31\% of whites, $20 \%$ of minorities), college debt has also risen, 19\% from 2007 to 2011 (Brooks \& Weidrich, 2012).

Utilizing a state-to-state comparison, the authors found that states with strong policies for programs that increased financial security had fewer residents who were asset poor. Vermont had the lowest rate of asset poor residents $(15.7 \%)$ compared to Nevada (45\%), the highest rate of asset poor residents. Vermont consistently had policies in place to assist residents with financial security whereas 
Nevada did not (Brooks \& Wiedrich, 2012). In addition, the authors noted that disparities across race were significant with "people and households of color" (any non-white resident) holding much less assets than white residents. According to Brooks and Wiedrich, policy and program reform is needed to assist Americans in reducing disparities and gaining financial health. Understandably, persons with a safety net are better able to recover from sudden income loss, unexpected medical bills and/or divorce. Unfortunately, some policies make asset building difficult or unrealistic for people in the mid- to low-income brackets (Brooks \& Wiedrich, 2012).

\section{Financial Empowerment Interventions}

Another intervention to improve one's economic stability is providing financial literacy (also referred to in the literature as education or empowerment). Studies suggest that long-term economic stability may be achieved by providing the necessary knowledge for one to make sound financial decisions regarding saving money, however the impact of these findings varies among the different studies (Bayer, Bernheim, \& Scholz, 2009; Bernheim \& Garrett, 2003; Clark, Morrill, \& Allen, 2012; Collins \& O’Rourke, 2010; Fox, Bartholomae, \& Lee, 2005; Gale, Harris, \& Levine, 2012; Hogarth, 2006; Letkiewicz \& Fox, 2014; Lusardi \& Mitchell, 2008; Lusardi, Mitchell, \& Curto, 2010; van Rooij, Lusardi, \& Alessie, 2012). Hogarth (2006) prepared a financial literacy paper for an international conference that provided a review of the effectiveness of financial education incentives and noted that an improvement in financial knowledge can lead to an improvement in economic status (savings, debt reduction, budgeting) (Hogarth, 2006). The author summarized 29 different financial literacy interventions implement during the years of 1995-2006. A program evaluation of the National Endowment for Financial Education curriculum cited a studentcentered intervention, noting improvements in financial knowledge, skills, and confidence in managing money across a 3-month time span. A more current evaluation has been completed, noting similar findings (Danes, 2012). The evaluator examined data compiled from 4,794 high school students (primarily juniors and seniors). Evaluators conducted curriculum surveys (using a post-then-pre methodology), as well as a 3month follow up survey (381 completed the follow up survey). Immediately after the curriculum, students saw significant improvements in level of understanding for all financial knowledge questions. These questions included career choice, credit cards, checking account, debt, credit rating, auto insurance and thinking about purchases. Additionally, positive financial student behaviors significantly increased 
following the training, and $66 \%$ of the students felt confident making financial decisions (up from $41 \%$ at baseline). At 3-months post curriculum, gains were again noted in 5 of the 7 financial questions, positive financial behaviors continued to be documented and $79 \%$ of students reported being confident making financial decisions (Danes, 2012).

A second student-targeted study examined financial education curriculum adopted at the state level and subsequent financial health later in life. The authors noted that in states where the curriculum was mandated, adults who attended high school in that state saved an average of $1.5 \%$ more than adults who attended high school in states without the mandated curriculum (Bernheim, Garrett, \& Maki, 2001). A follow up study by Cole and Shastry (2008), however, utilized a larger data set (U.S. Census Bureau) and did not find a significant difference (Cole \& Shastry, 2008).

Research on work-related financial education showed higher savings among the employees who worked for companies that provided such services (Bayer et al., 2009; Bernheim \& Garrett, 2003; Cho, Gutter, Kim, \& Mauldin, 2012; Clark et al., 2012; Gale et al., 2012; Hogarth, 2006; Jappelli, 2010; Lusardi \& Mitchell, 2008; Lusardi et al., 2010; van Rooij et al., 2012). Using data from a national telephone survey, Bernheim and Garrett (2003) found that employees of organizations where financial education was offered had higher overall savings compared to employees of organizations where financial education was not offered. Providing further insight, Bayer et al. (2009) used employer surveys to show that when seminars were offered (as opposed to distributed written materials), lower-compensated employee savings were higher. In addition, a positive correlation existed among saving rates and frequency of seminars (Bayer et al., 2009).

Still other studies have looked at lending institutions to improve asset building and thus target the SDOH component of economic stability (which intersects with income in both poverty outcomes and SES outcomes). Researchers examined the role of financial education, empowerment and access to traditional financial services and impact on individual and population economic stability and noted a relationship between low-income, lack of financial education and lack of banking practices (Amuedo-Dorantes \& Pozo, 2005; Brooks \& Wiedrich, 2012; Grimes, Rogers, \& Smith, 2010; Hawkins \& Kim, 2012; Phillips \& Stuhldreher, 2011; Rhine \& Greene, 2006; SF Office of Financial Empowerment, 2014). AmuendoDorantes and Pozo examined Mexican immigrants and the use of banking systems and money transferring 
systems. The study showed that those who had access to banks, through either understanding banking practices or proximity, and who worked consistent hours, utilized the banks to transfer money back home. Those who lacked the understanding of traditional banking practices (i.e. how to open a checking account), did not live in close proximity to a bank (often more rural areas), and/or worked less consistent and fewer hours, utilized more of the nonbank money-transmitting services. In addition, areas where poverty was higher had less traditional banking establishments available and more financial institutions charging high interest rates, thus further impeding opportunity for low-income populations to gain experiential financial education and to break the poverty cycle (Amuedo-Dorantes \& Pozo, 2005). Rhine and Greene had similar results. The researchers examined determinants of being unbanked among U.S. immigrants and found that immigrants with lower education and income level and larger families were more likely to use nonbank financial institutions (Rhine \& Greene, 2006).

A financial empowerment program, Bank On San Francisco, provided data supporting similar findings, noting that in 2005, 1 in 5 Californians, and half of the Latino and Black populations, did not have bank accounts. The majority of these individuals were considered the "working poor" (Phillips \& Stuhldreher, 2011, p. 1). Without bank accounts, individuals were spending between $2-5 \%$ of their income simply cashing their paychecks. In addition, lack of a bank account put individuals at significant risk of losing their money to theft and/or disaster (house fire, flood, etc.). These issues, coupled with difficulty in receiving low interest car/house loans and saving for the future, kept people in a poverty trap. Unbanked individuals faced several barriers to rising above the poverty level (Phillips \& Stuhldreher, 2011). Bank On utilized a model that incorporated the education of banking practices and marketing strategies to the community, city leaders, and regional banks. On a quarterly basis, partnering banks report the number of first time bank accounts opened to adults, the number of second chance accounts opened (due to an overdraft and failure to pay the bank on the first account), and the number of accounts opened with a locally provided financial empowerment certificate (signifying the individual participated in a financial empowerment program). Bank On San Francisco documented improved financial empowerment outcomes with over 10,000 checking or saving accounts opened each year in San Francisco since 2006. (Phillips \& Stuhldreher, 2011; SF Office of Financial Empowerment, 2014; Willenbrink, 2015). 
Also associated with lending establishments are Individual Development Accounts (IDAs). IDAs are utilized to assist low-income individuals in saving money towards a home, higher education, or a small business. Individual contributions to the savings are matched by government funds. The idea of IDAs, first proposed by Michael Sherradan in 1991, was to improve assets among low-income individuals and thus help alleviate poverty. In 1998, states began establishing Individual Development Accounts and currently 35 states in the United States offer IDAs; over 50,000 Individual Development Accounts exist(GrinsteinWeiss et al., 2008). A review of the IDA literature found that while saving is occurring, the resulting home ownership, schooling or microenterprise is not. The authors examined 14 peer-reviewed outcome studies and noted that there was not enough evidence to support Individual Development Accounts in developing assets, however evidence did suggest that the financial education provided by some IDAs may assist individuals in making financial decisions (Richards \& Thyer, 2011).

A final area of financial empowerment intervention is at the community level. A successful program to note is New York (NYC Department of Consumer Affairs Office of Financial Empowerment, 2013). NYC started a program to improve the financial health of its residents in 2006 with the creation of the Office of Financial Empowerment (OFE), a division of the Department of Consumer Affairs. The OFE set three over-arching goals: "Empowering individuals with low incomes by ensuring that they have sufficient knowledge to make financial decisions in their own best interest; Increase financial stability in low income households by increasing assets, decreasing debts, and boosting incomes to help families meet their present and future needs; Make NYC's financial marketplace safer by diminishing predatory practices and increasing access to appropriate and affordable products and services" (NYC Department of Consumer Affairs Office of Financial Empowerment, 2013, p. 10).

New York City saw the need to make financial empowerment part of the many services available to low income populations. Rather than use financial empowerment as an additional component, the Office of Financial Empowerment dictated financial empowerment be integrated into the social services already in place. The Office of Financial Empowerment fostered strong partnerships with city agencies to ensure an understanding of the importance of financial empowerment of low-income families and individuals and then utilized pilot studies to demonstrate the positive impact of financial empowerment across the levels of social services. Data were collected via social service providers from client meetings. This information was 
then verified through bank statements, loan statements, and credit score print outs and inputted into a large database. Outcomes included, among others, debt reduction, increased savings, and improved credit scores (NYC Department of Consumer Affairs Office of Financial Empowerment, 2013).

Locally, in 2012, Louisville joined the Cities for Financial Empowerment (CFE) Coalition, along with NYC and San Francisco, and began following the above models, working with local banks to offer products to mid- to low-income individuals and implementing financial empowerment training at the social service provider level across multiple city-provided financial resources. Family Scholar House works with the Louisville Metro Government and implements this financial empowerment training for their case managers. Because the program is still new, government officials have not tracked financial health outcomes. However, pre and post surveys given at FE trainings have noted at least short term improvements in social service provider's financial knowledge as well as confidence in discussing finances with their clients (Lentz, 2014).

A program evaluation done on the original financial empowerment program that is currently used by Family Scholar House noted significant improvements in financial literacy among program participants at two locations (Kerrick, Alzate, Hunt, Marciszko, \& Saylor, 2011). The evaluation consisted of an analysis of pre and post financial literacy surveys, participant evaluations and post training debriefing sessions. The training was conducted over a 6 week period, once a week for 2 hours each meeting. Qualitative data suggested the program was highly valued with $100 \%$ of the participants recommending the program to others. In addition, common themes surfaced regarding saving money, paying off debt, creating and maintaining a budget and setting goals. At this time, however, no long-term or behavioral change data has been collected on the program.

\section{Summary}

Research indicates multiple factors influence both individual and population health, and SDOH need consideration when developing interventions designed to improve health. Financial empowerment is a newer idea in the public health realm, only recently crossing over from economics and social work, and little research has been done indicating the role of financial empowerment in health improvements. By utilizing a local program that implements financial empowerment among its caseworkers and is focused at 
reducing poverty by improving self-sufficiency, the current study will add to the knowledge base by examining the role financial empowerment has in quality of life health outcomes. 


\section{CHAPTER 3: METHODS}

The researcher utilized a mixed methods approach to answer the following three research questions: To what extent is participation in the Family Scholar House (FSH) program related to healthrelated quality of life (HRQoL) for single mothers? To what extent is HRQoL related to the amount of time a single mother has been in the FSH program? What relationship does financial empowerment (FE) have with HRQoL for FSH participants? This approach combined quantitative components (FSH participant answers given in an online survey, utilizing national survey results as a comparison group) and qualitative components (participant answers given in an open-ended focus group discussion). Use of a mixed methods approach allowed for a better understanding of the data analyzed than use of either approach separately (Creswell, 2006; Roberts, 2010). Specifically for the current study, because the research questions gleaned information that takes into account a quantifiable survey score as well as beliefs about factors contributing to HRQoL, a mixed methods approach was an appropriate choice. For the quantitative data, the researcher used a between group design with the FSH participants and matched survey respondents from the Behavioral Risk Factor Surveillance System (BRFSS). The BRFSS group served as the comparison group. The researcher assessed the following dependent variables for each group: overall HRQoL score, physical health score, mental health score, functional status score and health ranking. The researcher compared these dependent variables to determine the effects of participating in the Family Scholar House program on HRQoL in single mothers. If differences were noted, post hoc testing assisted in identifying where the differences were, and a trend analysis assisted in determining if HRQoL was a function of time within the Family Scholar House program. In addition, the researcher also used a correlation explanatory design with length of time in the Scholar House program (pre-residential, year 1, year 2, year 3, year 4, and graduate), overall HRQoL score, physical health score, mental health score, functional status score, health ranking and demographics representing the variables of interest. The researcher explored the extent to which the variables co-vary.

\section{Sample}


The population for the current study consisted of six sub-groups: pre-residential, residential (year 1, year 2, year 3, and year 4), and graduate Family Scholar House participants in Louisville, Kentucky. At the time of data collection, there were 28 families in the pre-residence stage, 215 families in the FSH residential program, and 132 graduates. Utilizing Survey Monkey, a Scholar House administrator sent the HRQoL survey out, via email, to all the members of the categories listed above. To be in the program, participants must have a high school diploma or GED, thus the researcher assumed all participants could read and understand the survey. The Scholar House administrator also gathered demographic information on all the above participants. This information allowed the researcher to determine if the sample was descriptive of the Family Scholar House population. The researcher chose the sub above groups within the program based on feedback from the FSH administrator. In pre-residency, the participants struggle with unstable housing. During the first year in the program, participants adjust to the stable housing, the residential environment, and new responsibilities such as being a full-time student and managing a household budget. After the first year, participants continue gaining confidence with stabilizing school, work and home life (Fetalver, 2014). Thus, the division of the participants into the six sub-groups was appropriate.

The researcher performed a power analysis to determine the minimum response rate needed for high power (.80) and an effect size using Cohen's $\mathrm{d}=0.4$, which was comparable to current literature for HRQoL(Chisolm et al., 2007), while keeping a low alpha error rate of 0.05. Family Scholar House had 215 residential participants (year 1-4). With 28 participants in pre-residence and 132 graduates, the number of participants surveyed was 375 . G-power calculations determined 90 respondents were needed to maintain the above power and effect size (Faul, Erdfelder, Lang, \& Buchner, 2004) which was just below the projected survey response rate of 30\% (Baruch, 2008).

The population for the focus group discussions consisted of the same FSH participants. In the emails sent to the participants, volunteers were requested, on the email and on the survey, to sign up for the focus group. The researcher's contact information was provided on the email and the survey. The researcher offered an incentive of a $\$ 20$ gift card, food, and free childcare (childcare provided by Scholar House volunteers) for focus group participation. Dates and times for the focus groups were chosen by a 
Family Scholar House administrator based off the Scholar House activity calendar, choosing times when FSH participants were likely to be on campus.

\section{Participant Survey}

\section{Measures}

Health-related quality of life (HRQoL) is defined by the Centers for Disease Control and Prevention as "an individual's or group's perceived physical and mental health over time" (p.8) (Centers for Disease Control and Prevention, 2000). The CDC and partners developed an assessment tool to measure HRQoL (Centers for Disease Control and Prevention, 2000; Moriarity, Zach, \& Kobau, 2003). Criterion validity testing shows the HRQoL to be valid when compared to the "gold standard" of QoL scales: the SF-36 (Moriarty \& Zach, 1999). In addition, test-retest reliability scored moderately to excellently reliable (0.580.75) (Andresen, Catlin, Wyrich, \& Jackson-Thompson, 2003).

The HRQoL measure consists of the following four core questions:

1. Would you say that in general your health is excellent, very good, good, fair, or poor?

2. Now thinking about your physical health, which includes physical illness and injury, for how many days during the past 30 days was your physical health not good?

3. Now thinking about your mental health, which includes stress, depression, and problems with emotions, for how many days during the past 30 days was your mental health not good?

4. During the past 30 days, for about how many days did poor physical or mental health keep you from doing your usual activities, such as self-care, work, or recreation?

An additional set of 10 questions can also be used with the core four items; five questions focus on functional status (activity limitations and activity-related care) and five questions focus on symptoms (pain, depression, anxiety, vitality, and sleeplessness). Research studies have validated both the core four and the full 14-question survey (Centers for Disease Control and Prevention, 2000; Moriarity et al., 2003). The researcher utilized four of the ten HRQoL questions available from the CDC. In addition to the survey, the researcher asked demographic questions regarding age, ethnicity, parent education level, sibling education level, and number of children, as well as a curriculum ranking scale to help ascertain which aspect of the FSH curriculum the participant felt most affected her HRQoL. To encourage honest answering of the survey questions, anonymity and confidentiality were preserved. 
The CDC began collecting national and statewide data from the HRQoL beginning in 1993 (Moriarity et al., 2003). For this study, data collected from the Kentucky Department for Public Health, specifically the HRQoL collected with the Kentucky specific Behavioral Risk Factor Surveillance System (BRFSS), was utilized as the comparison group (Commonwealth of Kentucky, 2014). BRFSS, conducted since 1985 , is a randomly administered telephone survey used to provide national estimates of health behaviors (Commonwealth of Kentucky, 2014). In addition, the researcher also gathered from the BRFSS data the following demographics: age, ethnicity, parent education level, sibling education level, and number of children. This information was gathered as a comparison for the FSH group that informed on how representative the sample is of the population.

\section{Data Collection}

The first email was a prenotice letter, outlining the research study, providing contact information for any questions or concerns, and alerting the participants of a future email to be sent with a link to an online survey. This first informational sheet also had information about the focus group discussions, recruiting volunteers. The prenotice letter was emailed on a Thursday with the survey link emailed out on the following Monday. With the survey link, the researcher had a cover letter reminding the participants of the prenotice email, and encouraging the participants to complete the online survey as well as sign up for a focus group discussion. This letter also explained the purpose of the study, how the data will be used, and gave a contact number for any participants needing assistance completing the survey or for any questions or concerns. A reminder email was sent to the participants the following Mondays for four consecutive weeks, reminding participants to take the online survey (U.S. Census Bureau, 2014).

All data collection was done via Survey Monkey which was then downloaded into an Excel document and imported into the Statistical Package for the Social Sciences 22.0 (SPSS, 2014). Only the number on the survey response identified the participants.

\section{Data Cleaning/Management}

The researcher utilized SPSS to clean and manage the data. The data were explored and described using histograms and bar graphs. Data description and exploration allowed the researcher to determine if the data met the testing requirements of normality and homoscedasticity and to check for any outliers. Data that was determined to be non-normal, via a Kolmogorov-Smimov test of significance (where significance 
$<0.05$ notes non-normality), was transformed using a $\log +1$ transformation (Howell, 2013). The researcher examined data that contained outliers to see if the outlier greatly influenced the distribution. By looking at the 5\% Trimmed Mean and comparing it to the actual Mean, the researcher determined that in all but one variable, the outliers did not greatly affect the distribution and thus were left in the data (Pallant, 2005). In the variable regarding "number of days where activity was limited", the 5\% Trimmed Mean and the actual Mean different greatly. Closer examination noted two outliers; 365 days and 120 days. In order to include the data in the analysis but not allow these two data points to distort the statistics, the researcher changed the data points to 60 days, respectively, to match the third highest data point. Doing so brought the 5\% Trimmed Mean and the actual Mean closer, thus not distorting the statistics. Finally, the researcher conducted an Fmax test of variability and the Levene's test to ensure homogeneity of variance was not violated (Pallant, 2005). Cases were excluded pairwise as answers to the questions were not dependent on one another and therefore individual variables could be analyzed even if the data set was not complete (Pallant, 2005).

Data Analysis

The researcher used a one-way analysis of variance (ANOVA) to test for statistical differences between the means of multiple groups. This was an appropriate test to choose as the researcher was looking for differences between the BRFSS data and the six sub-groups of the FSH participants. When differences were noted (signified by a large F ratio indicating more variance between the groups than within the groups), pair-wise post hoc comparisons were conducted utilizing the Bonferroni post hoc testing to compensate for error rate inflation, maintaining the overall Type 1 error at 0.05 . In addition, when the researcher noted differences in the initial one-way ANOVA, a trend analysis followed to determine if the differences were a function of time in the program (Howell, 2013). The analysis was done as follows: overall healthy days (healthy days per month from questions \#2 and \#3 of the core four HRQoL questions) from each of the six sub-groups of FSH and a matched BRFSS population (age, gender, marital status, children in the home, Jefferson County resident) followed by the same comparison for physical health (question \#2), mental health (question \#3), functional status (question \#4), and health rating (question \#1). From this initial ANOVA, the researcher analyzed the differences using a post hoc Bonferonni test as well 
as a trend analysis. A second ANOVA was utilized to test differences between the six sub-groups of the FSH population regarding an additional five HRQoL questions asking about symptoms.

Following the guidelines set forth by the CDC for overall health days, responses given from questions \#2 and \#3 were added together, not to exceed 30 days. The total number represented the number of unhealthy days per month. Number of healthy days per month was calculated by subtracting unhealthy days from 30. Physical health, mental health, and functional status were calculated in the same manner (Centers for Disease Control and Prevention, 2000; Moriarity et al., 2003). In addition, the rating scale from question \#1 was assigned numerical values with excellent receiving a 5 and poor receiving a 1.

To examine possible correlations noted in the data, the researcher utilized a Pearson product-moment correlation coefficient. This value allowed the researcher to note both positive (as one variable increase, so does another) and negative (as one variable increases, another decreases) correlations as well as the strength of the relationship (ranging from -1 to 1) between two variables. The researcher used the following variables in the correlation analysis:

1. health ranking

2. physically unhealthy days per month

3. mentally unhealthy days per month

4. days per month of activity limitations

5. healthy days per month

6. days per month that pain made it hard to perform usual routine

7. days per month that sadness made it hard to perform usual routine

8. days per month that worry or anxiety made it hard to perform usual routine

9. days per month that not enough rest was had

10. days per month that were full of energy

11. FSH housing rank, FSH education rank

12. FSH health and wellness rank

13. FSH financial success rank

14. Race

15. number of children in the home 
16. mother's schooling

17. father's schooling

18. sibling's schooling

19. participant's schooling

20. months in FSH

21. credit score

\section{Participant Focus Group}

Measures

The researcher conducted three focus groups for the Family Scholar House participants. Focus groups were utilized to generate data and insight regarding financial empowerment and the effect on the participant's HRQoL.The following questions were asked in the focus group discussions: From your perspective, what are some of the more important parts of the Family Scholar House program? What is different about your life after entering the Scholar House program? What do you do differently than you did before entering the Family Scholar House program? Has the program affected your ability to take care of yourself financially? How? Have the financial success classes changed how you deal with your money? How? When you think about your health, what would you consider to be "good health"? Has your health changed since you've entered the program? How?

\section{Data Collection}

To recruit focus group participants, the researchers utilized the online survey. In the pre-notice email, the informational page, and on the last section of the survey, participants were asked to indicate that they are willing to be contacted to participate in the focus group, providing contact information. The researcher then contacted these participants and signed them up for a focus group. The researcher offered free childcare (provided by FSH volunteers), a meal during the group, and a $\$ 20$ gift card for attending one of the three focus group sessions. Focus groups were conducted on three of the Scholar House campuses in a centrally located meeting room. Days and times were selected by and Family Scholar House administrator based on the FSH activity calendar, noting specific times when women were likely to be on campus. The researcher tracked anticipated attendance for the focus groups, with an aim of between 6-12 attendees per group. Each focus group discussion lasted one hour and was audio recorded on the 
researcher's cell phone for later transcription. Due to high attendance at the first three focus groups and representation from each of the four campuses, a focus group on the fourth campus was not conducted.

\section{Data Preparation and Analysis}

The researcher transcribed, verbatim, the focus group discussions. Following the iterative thematic analysis methods put forth by Bradley, Curry, \& Devers (2007) and Thomas (2006), these transcripts were reviewed, coded, and organized into related themes. The iterative process followed a micro to macro format. In the initial first coding process, any and all noted themes given from the participants based on each focus group discussion question were put on a conference room table. Under these themes, the researcher organized specific quotes from the discussion group transcription that fit each theme. After this initial coding, a secondary coding process occurred. During the secondary coding process, the researcher looked for common themes among the data already present on the table. This process moved from a micro to macro look at the data. New themes appeared, based on cross-over themes of the initial process, and the participant quotes were reorganized under these new themes. This process continued until the themes presented answered the research question put forth at the beginning of the study. This final thematic coding was presented to an FSH administrator for clarity and understanding, thus affirming and validating the data analysis (Bradley, Curry, \& Devers, 2007; D. R. Thomas, 2006).

This study was formally approved by the University of Louisville Institutional Review Boards in compliance with all the institutional and federal regulations concerning the ethical use of human volunteers from research studies. Informed consent was obtained from each subject. 


\section{CHAPTER 4: RESULTS}

\section{Introduction}

Several factors affect individual and population health. Among these are social determinants of health, noted by the Department of Health and Human Services to be economic stability, education, social and community context, health care, and neighborhood and built environment. Economic stability is also a factor in persistent poverty and low socioeconomic status, both linked to poor health outcomes.

Interventions designed to improve health for individuals and populations need to consider financial stability and the role it plays in health-related outcomes. Thus, the purpose of this study is to examine the effect financial empowerment can have in a person's HRQoL. This chapter presents the results of an online survey taken by Family Scholar House participants as well as information gathered from focus groups at three FSH campuses. The survey showed the relationship between Scholar House participation and HRQoL, and the focus groups provided insight into the role of financial empowerment and HRQoL.

This chapter is divided into three sections. The first section describes the participants, including demographics, selection process, and specific characteristics of the participants as they relate to this study, and the procedures for selecting and contacting the participants. This section also describes the participants in terms of specific variables of interest. The second section provides the results of the online survey (quantitative component) and the third section provides the results of the focus group discussions (qualitative component).

\section{Participants}

The population for the quantitative piece of the current study consisted of 28 pre-residential, 215 residential (year 1, year 2, year 3, and year 4) and 132 graduate Family Scholar House participants in Louisville, Kentucky. Ninety-two single female parents responded to part or all of the online survey. Of these respondents, nearly $90 \%$ were in the residential program. The average age of the respondent was 27 , with ages ranging from 18-45 years. The average number of kids in each household was just under 2 . The majorities of participants had a credit score of 550-599, and were in the FSH program for 13-24 months. 
Fourteen percent had knowingly been in the ChexSystem (a system that tracks checking account mismanagement including overdrafts). Comparing to the FSH program overall, $80 \%$ of survey respondents were African American (compared to $81 \%$ of the FSH population), $16 \%$ were Caucasian (compared to $15 \%$ of the FSH population), and $4 \%$ were Other (compared to $4 \%$ of the FSH population). In addition, $43 \%$ were in the program for less than 1 year (compared to $39 \%$ in the FSH population), $29 \%$ had completed 1 year of the program (compared to $41 \%$ in the FSH population), $9 \%$ had completed 2 years of the program (compared to $19 \%$ in the FSH population), $9 \%$ had completed 3 years of the program (compared to $18 \%$ in the FSH population), and $8 \%$ had completed 4 years of the program (compared to $1 \%$ in the FSH population). Thus, given the demographics that were able to be compared, the sample populations was representative of the full FSH population. Descriptive characteristics are presented in Tables 1.1 and 1.2. Sample selection was based on participation in the Scholar House program, as a pre-resident, a resident or a graduate. An FSH administrator contacted the participants via multiple emails. These emails described the study, asked for focus group volunteers (listing the researcher as the contact) and provided a link to the online survey. The email was sent out once a week over the course of four weeks. A pre-notice email was sent two days prior to the survey link being provided. Responses from the online survey were utilized to provide demographics and to compare HRQoL in FSH participants to a matched comparison group from the BRFSS data. Additionally, the online survey data provided correlations and a trend analysis regarding length of time in FSH and HRQoL. 
Table 1.1

FSH Demographics

\begin{tabular}{|c|c|c|c|}
\hline \multirow{6}{*}{ Race } & & $\mathrm{N}$ & $\%$ \\
\hline & & 80 & \\
\hline & African American/black & 64 & 80 \\
\hline & Caucasian/white & 13 & 16.25 \\
\hline & Hispanic & 2 & 2.5 \\
\hline & American Indian/Native Alaskan & 1 & 1.25 \\
\hline \multirow[t]{6}{*}{ Children in home } & & 80 & \\
\hline & 1 & 39 & 48.75 \\
\hline & 2 & 28 & 35 \\
\hline & 3 & 7 & 8.75 \\
\hline & 4 & 5 & 6.25 \\
\hline & 5 & 1 & 1.25 \\
\hline \multirow[t]{4}{*}{ FSH program } & & 79 & \\
\hline & pre-resident & 2 & 2.5 \\
\hline & resident & 71 & 89.9 \\
\hline & graduate & 6 & 7.59 \\
\hline \multirow[t]{8}{*}{ Credit Score } & & 79 & \\
\hline & $300-499$ & 11 & 13.92 \\
\hline & $500-549$ & 13 & 16.46 \\
\hline & $550-599$ & 18 & 22.78 \\
\hline & $600-649$ & 8 & 10.13 \\
\hline & $650-699$ & 3 & 3.8 \\
\hline & $700-749$ & 0 & 0 \\
\hline & 750-799 & 2 & 2.53 \\
\hline
\end{tabular}




\begin{tabular}{|c|c|c|c|}
\hline & don't know & 11 & 13.92 \\
\hline & never checked & 13 & 16.46 \\
\hline \multirow[t]{4}{*}{ ChexSystem } & & 78 & \\
\hline & Yes & 11 & 14.1 \\
\hline & No & 51 & 65.38 \\
\hline & don't know & 16 & 20.51 \\
\hline \multirow[t]{3}{*}{ Health Insurance } & & 77 & \\
\hline & Yes & 73 & 94.81 \\
\hline & No & 4 & 5.19 \\
\hline
\end{tabular}


Table 1.2

FSH self and family education

\begin{tabular}{|c|c|c|c|}
\hline \multirow{2}{*}{\multicolumn{2}{|c|}{ Highest grade in school completed by }} & $\mathrm{N}$ & $\%$ \\
\hline & & & \\
\hline \multirow[t]{7}{*}{ mother } & & 80 & \\
\hline & never attended & 3 & 3.75 \\
\hline & grades $9-11$ & 3 & 3.75 \\
\hline & grade 12 or GED & 20 & 25 \\
\hline & college 1-3 yrs & 36 & 45 \\
\hline & college 4+ yrs & 16 & 20 \\
\hline & don't know & 2 & 2.5 \\
\hline \multirow[t]{7}{*}{ father } & & 80 & \\
\hline & never attended & 1 & 1.25 \\
\hline & grades 9-11 & 6 & 7.5 \\
\hline & grade 12 or GED & 27 & 33.75 \\
\hline & college 1-3 yrs & 19 & 23.75 \\
\hline & college 4+ yrs & 5 & 6.25 \\
\hline & don't know & 22 & 27.5 \\
\hline \multirow[t]{7}{*}{ sibling } & & 76 & \\
\hline & never attended & 2 & 2.63 \\
\hline & grades 9-11 & 7 & 9.21 \\
\hline & grade 12 or GED & 19 & 25 \\
\hline & college 1-3 yrs & 26 & 34.21 \\
\hline & college 4+ yrs & 21 & 27.63 \\
\hline & don't know & 1 & 1.32 \\
\hline self & & 79 & \\
\hline
\end{tabular}




\begin{tabular}{lcr} 
less than 1 yr completed & 9 & 11.39 \\
\hline 1 yr completed & 22 & 27.85 \\
\hline 2 yrs completed & 26 & 32.91 \\
\hline$\underline{3 \text { yrs completed }}$ & $\underline{15}$ & $\underline{18.99}$ \\
4 yrs completed & 7 & 8.86 \\
\hline
\end{tabular}


For the qualitative component of the current study, the population consisted of 38 pre-residential and residential FSH female parents who took part in one of three focus group discussions (Table 1.3). This group consisted of residents from each of the four Louisville campuses. The researcher or an FSH administrator contacted focus group volunteers and gave the location, date and time of the focus groups. In addition, an FSH administrator at each campus alerted participants about the focus group on the same day, and some single parents, who were in close proximity, simply dropped in on the discussion. Responses from the focus group discussions were utilized to provide insight regarding the role financial empowerment has in HRQoL of FSH participants. Additionally, from the online survey, the respondents were asked to rank, in order of importance to improving their overall health-related quality of life, the four main aspects of the FSH program (housing, education, health and wellness, financial success). The respondents were asked to rank the aspect that most positively affected their quality of life with a 4 , and the aspect that least positively affected their quality of life with a 1 . Nearly $50 \%$ of the respondents ranked housing as the highest (4), followed by education (3), health and wellness (2) and financial success (1).

Table 1.3

Focus group demographics comparison

\begin{tabular}{|c|c|c|}
\hline \multirow[b]{2}{*}{ Year in program } & FSH overall & focus group \\
\hline & & \\
\hline less than 1 year & $39 \%$ & $26 \%$ \\
\hline 1 year & $41 \%$ & $16 \%$ \\
\hline 2 years & $19 \%$ & $29 \%$ \\
\hline 3 years & $18 \%$ & $13 \%$ \\
\hline 4 years & $1 \%$ & $13 \%$ \\
\hline
\end{tabular}

\section{Quantitative results}

Prior to any analysis, the researcher set a significance level of 5\%. This value was chosen for this study as an alpha level of .05 is a commonly accepted level of significance in the social sciences, allowing 5\% error rate of rejecting the null hypothesis (the means between the groups are equal) when it is, in fact, true. Keeping the significance level at $5 \%$ controlled for this Type I error. Thus, any $p$-values $\leq .05$ were found 
to be significant. The researcher calculated Eta squared by dividing the Sum of squares for between-groups by the Total sum of squares. In addition, because the data were positively skewed and therefore non-normal (failing an assumption of the tests used in this study), the data were transformed utilizing a log +1

transformation. A $\log +1$ transformation was used to normalize the data and account for data entries of 0 .

To answer the first research question, "To what extent is participation in the Family Scholar House (FSH) program related to health-related quality of life (HRQoL) for single mothers?" the researcher used a one-way analysis of variance (ANOVA) to test for statistical differences between the means of multiple groups. Participants were divided into five groups according to time in the FSH program (0-12 months, 1324 months, 25-36 months, 37+ months, graduate) and a sixth matched BRFSS group. Marital status (single), number of children in the household $(\geq 1)$, gender (female), age (18-49 yrs) and location (Jefferson Co. Kentucky) matched the BRFSS group. Because there were only two participants from the pre-resident group, no quantitative analyses were conducted with this sub-sample. The analysis tested for differences between the means of the six groups regarding the core four HRQoL questions:

1. Would you say that in general your health is excellent, very good, good, fair or poor?

2. Now thinking about your physical health, which includes physical illness and injury, how many days during the past 30 days was your physical health not good?

3. Now thinking about your mental health, which includes stress, depression, and problems with emotions, how many days during the past 30 days was your mental health not good?

4. During the past 30 days, approximately how many days did poor physical or mental health keep you from doing your usual activities, such as self-care, work, or recreation?

A statistically significant difference was found in the number of mentally unhealthy days per month for the six groups $\left[F(5,137)=3.4, p=.006, \square^{\square}=.11\right]$ (Table 2.1). Pair-wise post-hoc comparisons using the Bonferroni test indicated that the log transformation of mean days of mental health score for the $0-12$ month group $(M=.84, S D=.53)$ was significantly different from the mean days of mental health score for the BRFSS group $(M=.43, S D=.51, t(5)=1.77, p=.003)$ (Table 2.2). A second statistical difference was found in health ranking (Excellent to Poor) for the six groups $\left[F(5,137)=2.36, p=.04, \square^{\square}=.08\right]$ (Table 2.1). Pairwise post-hoc comparisons using the Bonferroni test failed to find significant differences between the 
means. The mean health ranking score for the 13-24 month group $(M=.66, S D=.11)$ was not significantly different from the mean health ranking score for the BRFSS group $(M=.57, S D=.13, t(5)=1.54, p=.067)$

(Table 2.3).

Table 2.1

One-way Analysis of Variance for differences in group means

\begin{tabular}{|c|c|c|c|c|c|c|}
\hline & & Sum of Squares & $\mathrm{df}$ & Mean Square & $\mathrm{F}$ & Sig. \\
\hline & Between Groups & .321 & 5 & .064 & .274 & .926 \\
\hline \multirow[t]{3}{*}{ Physical Hlth } & Within Groups & 31.864 & 136 & .234 & & \\
\hline & Total & 32.185 & 141 & & & \\
\hline & Between Groups & 4.564 & 5 & .913 & 3.410 & .006 \\
\hline \multirow[t]{3}{*}{ Mental Hlth } & Within Groups & 36.669 & 137 & .268 & & \\
\hline & Total & 41.233 & 142 & & & \\
\hline & Between Groups & 1.634 & 5 & .327 & 1.505 & .193 \\
\hline \multirow[t]{3}{*}{ Activity Restrict } & Within Groups & 25.180 & 116 & .217 & & \\
\hline & Total & 26.814 & 121 & & & \\
\hline & Between Groups & .054 & 5 & .011 & .247 & .941 \\
\hline \multirow[t]{3}{*}{ Overall Hlth } & Within Groups & 5.952 & 136 & .044 & & \\
\hline & Total & 6.006 & 141 & & & \\
\hline & Between Groups & .184 & 5 & .037 & 2.364 & .043 \\
\hline \multirow[t]{2}{*}{ Hlth rating } & Within Groups & 2.132 & 137 & .016 & & \\
\hline & Total & 2.316 & 142 & & & \\
\hline
\end{tabular}

Table 2.2 


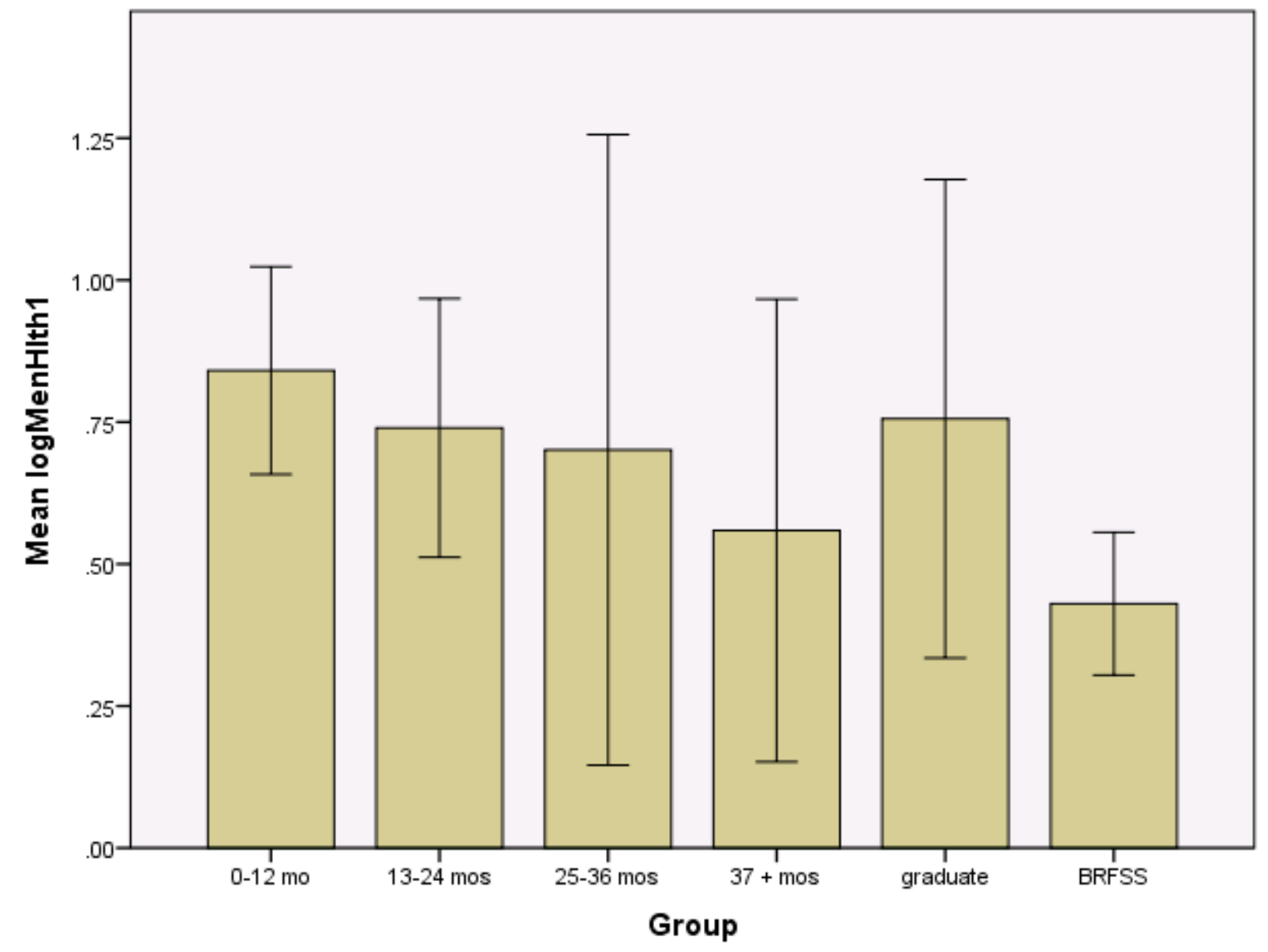

Error bars: $95 \% \mathrm{Cl}$

Table 2.3 


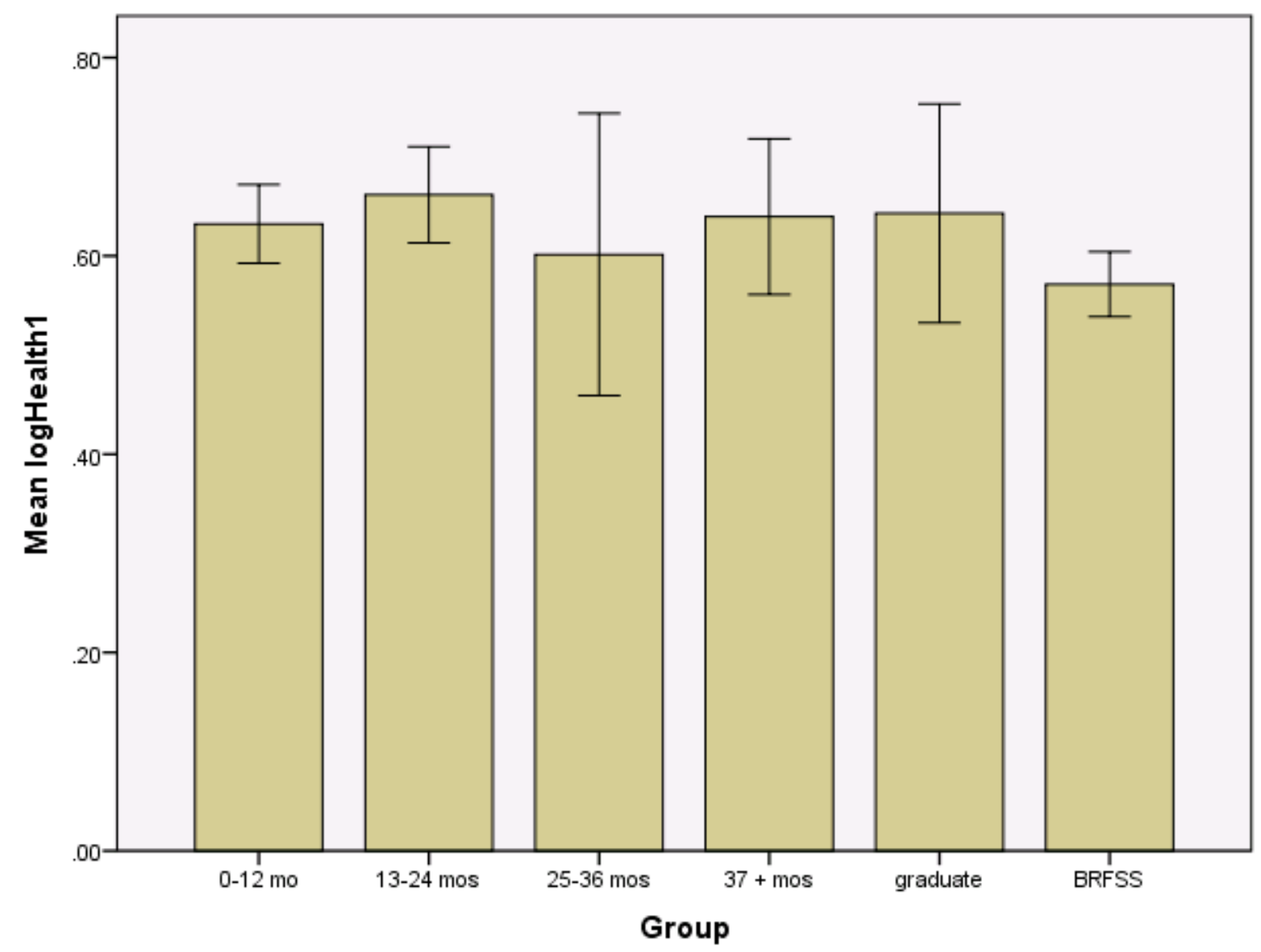

Error bars: $95 \% \mathrm{Cl}$

The researcher also conducted a second ANOVA to test for differences between the means of the five FSH groups regarding an additional five HRQoL questions:

1. During the past 30 days, for about how many days did PAIN make it hard for you to do your usual activities, such as self-care, work, or recreation?

2. During the past 30 days, for about how many days have you felt SAD, BLUE, or DEPRESSED?

3. During the past 30 days, for about how many days have you felt WORRIED, TENSE, or ANXIOUS?

4. During the past 30 days, for about how many days have you felt you did NOT get ENOUGH REST or SLEEP?

5. During the past 30 days, for about how many days have you felt VERY HEALTHY AND FULL OF ENERGY? 
From this analysis, the researcher found no significant differences.

To answer the second research question, "To what extent is HRQoL related to the amount of time a single mother has been in the FSH program?" the researcher conducted a trend analysis on the above significant findings (both mentally unhealthy days and health ranking), removing the BRFSS and graduate groups from the analysis. These groups were removed as they were not part of the times series. A trend analysis found no significant differences.

Relationships between the variables were investigated using Pearson product-moment correlation coefficient The researcher transformed the data utilizing a $\log +1$ transformation to maintain consistency throughout the full data analysis, ensuring no assumptions of linearity, normality and homoscedasticity were violated. The HRQoL variables were all significantly associated with each other. Because this might be expected with this type of measurement tool, these findings will not be discussed. There was a negative and significant correlation between length of time in the FSH and days of rest $[r=.27, n=80, p=.02]$, with $7 \%$ shared variance. Longer time in the FSH program was associated with lower days where the participant did not get enough rest or sleep. There was a positive and significant correlation between the financial aspect of the FSH program and more days of being in pain and thus less able to perform usual activities $[r=.29, n=80$, $p=.01]$, with $8 \%$ shared variance. Participants who had more days of pain ranked the financial success aspect of the FSH program higher. There was a significant and negative correlation between the housing aspect of the FSH program and days full of energy $[r=.25, n=.80, p=.03]$, with $6 \%$ shared variance. Participants who had more days per month where they felt full of energy ranked the housing aspect of the FSH lower. There was also a negative and significant correlation between the housing aspect of the FSH program and credit score $[r=.31, n=79, p=.007]$, with nearly $10 \%$ shared variance. Participants with a higher credit scored ranked the housing aspect of the FSH lower (Table 3).

Table 3.

$\underline{\text { Significant correlations for the FSH population }}$

Online survey measure

\begin{tabular}{llllllll}
\hline Measure & 1 & 2 & 3 & 4 & 5 & 6 & 7 \\
\hline 1. Rest & 1 & -0.16 & -0.01 & 0.12 & $\mathbf{- 0 . 2 7}$ & -0.14 & $\mathbf{0 . 3}$
\end{tabular}




$\begin{array}{lrrrrrrr}\text { 2. Energy } & -0.16 & 1 & \mathbf{- 0 . 2 5} & -0.06 & 0.05 & \mathbf{0 . 2 4} & \mathbf{- 0 . 2 7} \\ \text { 3. Rank of Housing } & -0.01 & \mathbf{- 0 . 2 5} & 1 & \mathbf{- 0 . 3 4} & 0.09 & \mathbf{- 0 . 3 1} & -0.9 \\ \text { 4. Rank of FinancialSuccess } & 0.11 & -0.06 & \mathbf{- 0 . 3 4} & 1 & -0.03 & 0.15 & \mathbf{0 . 3} \\ \text { 5. Months In Program } & \mathbf{- 0 . 2 7} & 0.05 & 0.09 & -0.03 & 1 & 0.04 & 0.05 \\ \text { 6. Credit Score } & -0.14 & \mathbf{0 . 2 4} & \mathbf{- 0 . 3 1} & 0.15 & 0.04 & 1 & -0.02 \\ \text { 7. Pain } & \mathbf{0 . 3} & \mathbf{- 0 . 2 7} & -0.09 & \mathbf{0 . 3} & 0.05 & -0.02 & 1\end{array}$

Note: All coefficients (in bold) are significant at the .05 level

\section{Qualitative results}

To answer the third question, "What relationship does financial empowerment have with HRQoL for Family Scholar House participants?" the researcher utilized three focus group discussions. The overarching theme to arise from the discussions was stress reduction. The different components of the FSH program reduced stress in the participant's lives in a variety of ways. The following individual participation quotations (noted by italics) were a sample of the responses given for each question.

"Just being in this program alone has lifted a lot of stress. I mean, I still have my daily stress, everyone does. But I feel like this program has just lifted a lot off of my plate so I don't have to worry about stuff all the time. Because of their support, I don't have to worry."

"They helped out so much that there is a reduced stress level than from prior to joining the SH."

“Since I've lived here, 2 people have said, “Wow! You don't cuss? How come you don't cuss anymore?" stuff like that. Once I started living here, it really reduced my stress level and my emotions were more stable."

"I'm just not stressed out all the time."

"Being in SH kind of takes the edge off. You're not so angry all the time, or bitter or frustrated with being in a situation you are." 
"For the first time since I've been in school, I don't have to work at all during the semester. It hasn't been so stressful financially. "

"There is less stress with housing and grants."

"The environment that some of us were living in before was not safe. It was real stressful. So moving in here took a lot of stress off of me."

The first focus group question asked participants about important aspects of the FSH program. While participants commonly mentioned housing and education, the underlying theme that developed from the discussion related to a network of support that Family Scholar House provided. Within this network, the participants were offered assistance with a multitude of different areas including housing (Section 8/income based), education (academic advising, scholarship/grant assistance, tutoring), and finances (future funds savings program, budgeting workshops, home ownership program, food/clothing/furniture assistance). "I know that before I moved in here, I had my own house for like $\$ 1200$ a month and I was just barely staying afloat. When I started school, I felt like, month after month, I started to have less and less for bills since I had to cut my hours for school. It's kind of impossible to afford rent."

"They (FSH) make sure you are on track to finish your degree. For me, this is my second time going through school. The first time I got half way through and dropped out. And the tutors are amazing."

"The thing I value the most is the opportunity to complete my education."

"I was in a bad situation and I know that education would keep me from being in this situation again." 
"I worked a lot of dead end jobs with no future. So I jumped from job to job, not really happy with any of them. And that made me go back to school because I want to be a professional, something that I can progress in, hold on to."

"If it wasn't for this program, I wouldn't be able to go back to school anytime soon, trying to work and take care of my kids."

"They have classes that teach you how to manage your finances which help you balance your rent and the utilities you have. That has been very helpful."

"I like that they have the "Future funds" savings program because I am horrible at saving. So every month we have to pay $\$ 10$ into our "future fund" and they when you move out, you get that money back. It's a great way to save."

"At Thanksgiving they will have free turkeys and free meals that you can come and pick up. And Christmas is one of the biggest things for people who celebrate Christmas and they can't afford to get their kids anything. Somebody else provides everything for them. Just about anything you want."

"I like that they have the basement, the food pantry, the clothing, the furniture and stuff. That was a lot of help and saved me a lot of money."

In addition, the participants recognized a positive environment that Family Scholar House provided. The community consisted of other single parents working towards a similar goal, a variety of children's activities, and a supportive Family Scholar House staff.

"I like the proximity of other parents who have kids. In the summers, we do cookouts every Friday. Before I moved here, I didn't have housing and I was depressed about that, but I also didn't have any friends. The one thing that FSH afforded me was friends." 
"We are all working towards the same goal. We are all single parents. We are all trying to better ourselves, not just for us, but for our children."

"For me, it's the things they do for the kids, like send them to football games, basketball games. I know that if I wasn't living here, my kids would be out of luck. "

"Scholar House gives you the opportunity to come back and start over. With the support staff, they are a big, big support to our education."

"They bring people in and you can network and meet people who can help you get a job."

The second and third questions were designed to identify different aspects of the participant's life since entering the Family Scholar House program. From this discussion, environment and school surfaced as common themes. Housing was an important aspect to a new environment for the participants. Because the housing was income based and residents receive a Section 8 voucher, many participants were able to spend less money on rent, save more money, and have extra money to take their children on family outings. This reduced the amount of stress felt by the participants.

"Housing alone took a world of stress off me. I had me and 3 kids living in the same room at my brother's house. That's a rough situation."

"I was working 50-60 hours a week. I would stress about the kids health and am I making enough money for the bills. Now I don't really worry about bills too much and we have extra money to go and do things that we enjoy."

“With my housing being taken care of, I have a little bit more time. I don't have to work as much as I did to make sure my bills were being paid."

"I've been saving money and making better choices with my money. SH has helped me with that a lot." 
"Everyone worries about having a roof over their head for their kids. That's the main concern and everything else just falls to the side. Now, we have a roof over our heads. So if we have extra money, we can maybe go to the movies or go skating."

In addition, because housing was stable and secure, the residents could work less, focus on school more and be involved in community and campus activities. This, in turn, gave them hope of a future outside of the cycle multiple jobs, unpaid bills and lost opportunity for higher education. Participant's confidence improved because of success seen in school while maintaining a full-time status and seeing a realistic graduation date.

"If it wasn't for SH, I wouldn't be able to complete my degree. I would be stuck in a dead end job, making minimum wage and stuck in that cycle over and over again."

"I was in school already, but the focus and the motivation to stay at the place I needed to be, as far as going to class, doing the homework, that, I didn't have the focus that I needed because I didn't have the housing."

"I feel like it just takes away a lot of the worry. Because of SH, I don't have to work as much and I can take the time to find a job that I enjoy and that works with my school schedule."

"I can focus on school and not worry about having a roof over my head."

"Before SH, I had to work. I was getting maybe 4-5 hours of sleep a night and trying to take 2 classes a semester. I just didn't have any time. Now, I have a lot more time."

"School can be my priority." 
“Before, I worked 2 jobs and would take a class but then I'd drop out because I needed to make money. Now I can focus on school and finish. Its confidence. Knowing I can do this because I have all this support."

"I spent a lot more time working before I got to this program. Now I've been able to develop a regime of self-care, which I've never done before. It was always work and kids. Here I have that luxury, that free time to actually do some of those things that I want for myself in addition to going to school."

The support staff, other single parents, community members, mentors and FSH graduates added positively to the new environment by providing consistent encouragement, hope, motivation, determination, and safe relationships.

“What really helps me out is when you're in an ordinary situation and you have to tell someone you live at the FSH and they're like, "I graduated from that program! You can do it! Don't give up!" So that makes me like, Ok. If they can do it, I can do it.",

"The support staff is always giving you a push. They understand. I know I can always go to them."

“It's genuine, how they talk to you. It's professional and genuine. They really care. It's not just a job for them."

“Before I moved to SH, I didn't have a lot of friends, so I would just hold my feelings in all the time. Here I can build relationships and be more open and social."

"The biggest difference for me is basically having a second family here. With the other parents and the support staff, I feel like it's an extended family that I never had. People who can guide your steps and people who have your best interest, truly, at heart." 
"You gain friends. I've known these 2 people since I moved in here and our little boys are best friends. It's just really good to have and know that someone is going through the same thing that you are going through. They literally do bring friends together."

"Scholar House has been so supportive from financial stuff to education to community support. If they can't help you, they'll let you know where to go to get help."

"Before SH, there was no hope."

"You don't have the choice to fail."

Within this environment, the participants also voiced noted improvement in their children's lives. Family Scholar House provides high-quality, stable housing for the children (often each child with his/her own room), a safe environment (each campus is essentially a gated community), a book club, workshops on parenting, and a strong early learning childcare program.

"It's easier being a parent."

"The environment that some of us were living in before wasn't safe for ourselves or our kids."

"My kids come home to the same bedroom."

"Knowing your kids have an apartment. And these are nice apartments."

"This is the longest my kids have ever lived in one place since they've been born."

"My son basically grew up with the same kids. I think that's been really, really important for my kid. To grow up with the same kids. Not just got a friend, lose a friend."

"The kids do better because they see us do better." 
"We are safe. We do have these gates to protect us."

"Just to have a building that is safe."

"I can go warm up my care and feel safe to leave the car. So it's warm for me and my child."

"My kids can go outside to the park and I know that they are okay. I feel secure."

"I feel safe. My whole thing is it's a gated community. People can't get in and out. And we're right next to a church. My son, he's only 8, he knows everybody gets killed in the West End so he doesn't really want to live there. But he's like, nobody's going to kill anybody by a church."

"My kids are in the Early Learning Center. And when they get into school, I know they will be way ahead of their other classmates. It's a really good program."

"Before I moved here I was with my mom and dad and they basically took care of my son. He was more like my brother. Now, we are always together and we are really bonding. Our relationship is much stronger."

The fourth question asked the participants how being in the Family Scholar House program affected their abilities to take care of themselves financially. From discussion on this question, themes related to saving money and Family Scholar House support re-surfaced. Regarding saving money, several residents commented on the future funds program. With this program, participants were required to give FSH ten dollars per month that is placed into a fund for the resident. Upon leaving the FSH program, this money is returned to the resident. Knowing that this money will be available upon graduation, residents commented on feeling secure and less apprehensive about leaving the program.

"I've been able to save money for when I move out." 
"SH has motivated me to save more."

"Not paying rent has allowed me to save more. Whenever I do move, I feel I am more prepared." Besides the future funds, residents were able to save money in their overall budget due to lower rent and bills. One resident paid cash for her first vehicle; a second resident paid a seven thousand down payment on a newer vehicle, relating the decision to keeping a lower car payment. Some residents were saving money for a home; others paid off debt.

“They pay our internet and show you that you don't have to have cable. That's $\$ 40$ a month. You can do Netflix for \$8. They always make sure you know your options so you don't put a financial strain on yourself."

"Instead of always struggling, SH showed me how to manage my money so I can pay for stuff that I need, like LG\&E. I can get caught up and not be behind all the time or in debt."

“In December, I bought a '06 Ford Fusion. And I feel so good about it. It was my money. It wasn't given to me. I didn't take out a loan. I was able to pay one amount and everything is in my name."

“With SH I am actually able to pay off my credit cards. I have been living so long on credit cards and I was actually able to pay it off. SH has helped me with a lot of debt. It's given me more freedom. Someday I want to buy a car, buy a house."

“I have more money saved. Last week my car broke down and it was \$500. I didn't want to spend it, but I had it to spend.”

In addition, several residents mentioned the support of Family Scholar House through "the basement". The basement contained food, clothing and furniture that are available to all participants. Some residents were able to get full living room sets, desks, and dressers as well as clothing for themselves and their children. The food pantry provided essentials towards the end of the month when money was scare. 
"The food pantry is a very nice program. If I am low on food, I can go get cereal, canned goods, and things like that. It all helps a lot. Saves you money if you need to go grocery shopping."

"In the basement, I can always find things for my daughter to wear. That saves me money all year long."

"I can get a lot of clothes for my kids. And with 4 kids, that really helps out."

"SH gave me a whole new living room. And its nice stuff, too."

Finally, participants mentioned holiday support, specifically Christmas and Thanksgiving, several times.

"Christmas and other holidays, those are helpful financially."

“You don't even need to get your kids anything. You just get a family that adopts you and gets you everything on your list."

"Christmas time is a big help financially. You can make a wish list and they get you everything. Clothes for the kids, pots and pans for me. Everything."

The fifth question sought to identify how the financial classes changed how the participants managed their money. The most common theme was the ability to understand finances, including credit, banking, budgeting and taxes.

"Before you can get into FSH you have to take a financial class. For me, that was important because if I hadn't learned that before I started out, then I wouldn't have been so conscious, making sure I pay everything on time. ”

"They have classes that people will come out from credit unions and give real valuable information on how to build your credit." 
"They teach you about credit cards."

"I think they point out a lot of expenses that you don't realize how much you're spending until it's pointed out to you. Like how much I spend on coffee. It adds up."

"They teach you about different types of banks. Things maybe your parents didn't teach you."

"I learned how to budget my money. I'm really tight now. And I coupon, even though I get food stamps. I'm really good with my money now."

The sixth and seventh questions focused on the participant's health since entering the FSH program. All agreed that health was comprised of physical, mental, emotional and spiritual aspects, and the residents felt that Family Scholar House supported each of these components. Participants noted access to a gym, healthy cooking classes (for parent and child), massage and art therapy, and health fairs improved the different components of health.

“When I first moved in here, I wasn't eating right or feeling right. Now that I've gotten in here, and stabilized, everything has just fallen in line. I feel healthy now."

"I've been learning about baby foods and formulas, making sure my kids eat right. If they eat right now, it helps their brains grow."

"Parkland has a kitchen where they teach healthy eating for kids. And kids can come."

"We all have access to a gym to work out. It's motivated me and my son."

"They have a massage therapist on Monday and Wednesday."

"This program has really helped me out. I'm in a 90 day weight loss challenge and they provide passes to the YMCA." 
"We have a nice gym. Everything is so nice, like the East End. Makes you want to go workout."

"I had high blood pressure at the age of 33 and I mean really high blood pressure. And I didn't really know the seriousness of high blood pressure. SH helped me to learn to take it seriously. I finally learned to start taking the medicine and my blood pressure has decreased a lot."

“Now that I'm not spending \$1000's and \$1000's on bills, I actually have money to go see the doctor and pay a co-pay."

"I've been able to seek out professional help when I needed it versus before it was $\$ 20$ for a copay and I was out of luck. I didn't have \$20 for a co-pay. I was a single mom working all those hours and paying all those bills."

In addition, the participants felt supported by the FSH mentally and emotionally through a variety of childcare options provided for each of the workshops, Mom's night out and study nights.

"SH has an opportunity where you can drop your kids off for 2 hours once a month and do whatever you need to do. Go shopping, do laundry, study. Whatever."

"All the classes have free childcare. That's a big deal."

Though the vast majority spoke very highly of the Family Scholar House program, a small group of women ( 3 of 38, all from the same Scholar House campus) voiced some frustrations with the program, commenting on the difficulty of being a full time student, a full time mom, working, and making time for the mandatory meetings and workshops.

"I think that coming here, I didn't know what I was signing up for and that affected a lot of my health. I didn't think it was technically going to be easy, but I didn't think it would be as hard as it was."

"I feel like the program isn't doable. Like I have to have some pretty superhuman capabilities." 
"I feel like there are more stressors in some respect because my housing is directly tied to my performance in school."

The researcher gained clarity on this feedback through validating the responses with an Family Scholar House administrator. Program requirements included full-time status in school, maintenance of a cumulative 2.0 grade point average, attendance at 5 mandatory meetings per month ( 1 workshop, 2 academic advising appointments, 1 office visit with a case manager, and 1 home visit with a case manager) and 4 hours of monthly community service. Because the requirements were daunting to some, administrators calculated the amount saved in housing and other bills per resident and found that, on average, each resident was paid $\$ 65$ per hour for the time spent on the mandatory meetings. While participants acknowledged the program was difficult, the vast majority of the focus group discussion members spoke highly of the design and the staff.

"I feel like SH is one of the best things Louisville has to offer single mothers. I just feel like it is one of the best ways to stimulate the economy. You have more women getting degrees. I just think its good overall for individuals and for the community as a whole."

"SH sets you up. I mean, right now, you might not have much money going through school and stuff, but you have the chance to go to school and graduate and then work in a job where you can earn as much as you need. You can support yourself."

"I really don't know where I would be or what I would be doing right now if I weren't here. It is a true blessing. I am definitely on the right track."

"A lot of women have kids in bad situations, drugs, domestics, and they've lost hope. SH gives us hope."

"SH are not only saving our lives, they are saving our children's lives, our future grandkids lives. Everything. It's a cycle, but now it's a different cycle. It's a beautiful thing." 
"Before SH I was homeless, living in a shelter, suicidal, had attempted suicide and I felt like God gave this to me. So I see how all of it works together. SH was a true blessing to me and my children, a light...I was really at my wits end...they saved my life."

\section{Summary}

The Family Scholar House program was a unique intervention designed to stop the cycle of poverty by providing college education and support to single parents. The different aspects of the Family Scholar House program addressed each of the five social determinants of health (economic stability, education, social and community context, health care, and neighborhood and built environment). Results of the studies showed that participant's mental health and general health rating, as measured by a HRQoL survey, improved during the time in the FSH program. Upon graduation from the program, the mental health and the health rating of the FSH participant's was no longer significantly different from the BRFSS comparison population. Qualitative results indicated that this improvement might be related to the decrease in stress due to the network of support provided to the FSH participants. Thus, the study provides evidence that participation in the Family Scholar House program may improve components of health-related quality of life. 


\section{CHAPTER 5: DISCUSSION}

\section{Introduction}

Numerous factors affect individual and population health. Among these are social determinants of health, noted by the Department of Health and Human Services to be economic stability, education, social and community context, health care, and neighborhood and built environment. Economic stability is also a factor in persistent poverty and low socioeconomic status, both linked to poor health outcomes.

Interventions designed to improve health for individuals and populations need to consider financial stability and the role it plays in health-related outcomes. Thus, the purpose of this study was to examine the effect financial empowerment can have in a person's HRQoL.

\section{Discussion}

The social determinants of health include economic stability, education, social and community context, health care, and neighborhood and built environment. Using these as a framework to improve health outcomes, the researcher examined the different components of the Family Scholar House program as related to HRQoL. The researcher hypothesized that participation in the program was related to an improved HRQoL and that the longer a participant was in the program, the more improvement in HRQoL was noted. In addition, the researcher hypothesized that financial empowerment positively affects HRQoL and that those who are provided financial empowerment will have an improved HRQoL. The HRQoL measurement tool that was utilized included measures of physically unhealthy days, mentally unhealthy

days, activity limitations due to unhealthy days, and a general health rating. Improvements in mental health days and the general health rating were found. By graduation from the Family Scholar House program, resident's mental health and general health rating were no longer significantly different from the BRFSS comparison group. In focus group discussions, a common theme of stress reduction emerged. People living in the lower SES categories experience higher levels of stress that are associated with poor mental and general health (Backlund et al., 2007; Backlund et al., 1996; Gallo \& Matthews, 2003; Myers, 2009). More specifically, mothers report fatigue and chronic mental and physical health problems resulting from 
financial strain, parenting stress and lack of support (Oyserman, Bybee, Mowbray, \& Kahng, 2004; Schwartz, Bybee, Spang, Rueda-Reidl, \& Oyserman, 2000). Participants in the Family Scholar House program felt that the design of the program reduced the stress in their lives through a variety of ways, including stable housing, reduced work hours, financial support, educational support and overall staff support. The researcher paired each of the emerging themes with a social determinant of health, providing a framework for the noted improvements in mental health and general health rating. The improvement seen in the self-reported general health rating complemented the improvement in mental health.

To answer the first two research questions, "To what extent is participation in the Family Scholar House (FSH) program related to health-related quality of life (HRQoL) for single mothers? To what extent is HRQoL related to the amount of time a single mother has been in the FSH program?" the researcher examined the social determinants of health for neighborhood and built environment, education, social and community context and health care.

\section{Neighborhood and built environment (Housing)}

According to the focus group discussions, stable housing reduced stress levels among the participants. All residents in the Family Scholar House program were homeless before moving into a Scholar House apartment. Becoming a resident reduced the stress associated with unstable housing. The apartments were high-quality, furnishings were provided if needed, and rent was Section 8/income based (residents paid $30 \%$ of their income towards rent). In addition, the apartments were located behind secure gates, had playgrounds for the children, and were located in a community of like-minded individuals all working towards positive life-style changes. The single parents and their children had stable, safe housing that was supported by a positive healthy environment. A large body of literature that notes the effects of stable housing on mental health supports this finding. An analysis of the literature noted that poor-quality housing increases psychological distress and thus creates poor mental health among those who live in such environments (Evans, 2003). The authors examined the different types of housing structures and the direct and indirect influences of such variables as lack of play area for the children, safety, a healthy social community, and condition of the structure.

Housing also reduced stress by alleviating the need for the participants to work. As mentioned previously, Family Scholar House housing was income based. Thus, participants could reduce their 
workload, or in some cases, stop working altogether, yet still maintain stable housing. Several participants commented on life before Scholar House, working 50-60 hours a week only to struggle paying rent. Because they were working so much, college was unrealistic and opportunities for improving their longterm financial status non-existent. Once in Family Scholar House, the design of the program allowed participants to reduce their workloads and maintain a full-time status in college, providing hope for longterm financial stability and self-sufficiency. The workload reduction also provided the residents an opportunity to spend more time with their children, learn parenting skills through the Scholar House workshops, and create a healthy, balanced environment for both themselves and their children. These findings support a large body of research citing an association between low SES and poor health (Adler et al., 1994; Backlund et al., 2007; Gallo \& Matthews, 2003; Gornick, 2002; J. W. Lynch et al., 2004; J. W. Lynch et al., 2005). Though Family Scholar House residents were still living below the poverty level, the reduction of work hours, improved educational status, and access to resources may have improved their SES and health.

Education (Academic support)

Along with stable housing and financial support, the participants received guidance and assistance with pursuing their college degrees. Academic advisors provided information on scholarships and grants, and educated the participants on the differences and opportunities provided with degree and certification programs. Tutors were available to assist not only the residents, but also the children. Since housing was stabilized, participants could focus on school, attend full-time, and see a "light at the end of the tunnel" with a realistic graduation date. The participants commented on earning potential associated with a higher education and while the demands of the Family Scholar House program academically were challenging, there was an understanding that they would graduate from the program better prepared for self-sufficiency, leaving the cycle of poverty. This belief gave hope, motivation and determination to the participants, thus improving their mental state. When considering the role of obtaining a higher education degree, this finding supports a study by Chevalier (2006) who found that education serves as a protective factor to poor mental health, more so in women (Chevalier \& Feinstein, 2006). When considering self-efficacy, this concept is a core criterion in multiple mental and physical health promotion and prevention models.

Social and community context (FSH staff support, FHS community) 
Finally, support from the staff at each of the four Family Scholar House campuses reduced mental stress. Residents made several comments regarding the network of support the residents felt they had in place, calling the Scholar House a "second home". Staff was available to assist with academic advising and case management, supporting the residents in a multitude of ways. A primary source of support provided by the staff was assisting the residents with knowing and accessing available resources. For instance, if a resident qualified for Temporary Assistance for Needy Families (TANF) benefits or academic scholarships and grants, the staff would provide the assistance needed to ensure the resident was able to utilize these resources. In addition, the staff also organized (and sometimes conducted) different workshops for the residents, provided childcare at events, organized holiday parties, served as a sounding board for frustrations and a source of encouragement when needed. One resident credited the staff with saving her and her children's lives by giving her a second chance. These findings support the work of several authors who found that lower levels of perceived support among single mothers, particularly those in poverty, were associated with chronic stress and poor mental. Social support provided a buffer against deteriorating mental health and was necessary to improve mental health (Cairney, Boyle, Offord, \& Racine, 2003; Hashima \& Amato, 1994; Olstad, Sexton, \& Søgaard, 2001).

In addition to the support staff, the Scholar House community assisted with mental health improvements among the participants. Residents commented on the unstable, unhealthy, and at times dangerous, backgrounds many of them had come from. Recognizing that the community around them influenced their choices, the residents saw the importance of being in a place where everyone had overcome the same barriers and was working towards the same goals. Several of the parents pointed out other residents with whom they had spent the last few years, building healthy friendships and bonds and watching their kids grow together. Family Scholar House graduates and mentors were also source of support, encouraging the residents to finish the program and focus on the end goal. These findings support the work of Tischler et al. (2007) who found that homeless mothers valued the support of social service staff and other homeless parents, feeling this support improved their own mental health (Tischler, Rademeyer, \& Vostanis, 2007).

Health care (FSH workshops, facilities) 
The Family Scholar House program, through various workshops and health fairs, and access to a workout facility met this final social determinant of health. People in the lower SES categories experience poorer health due to limited or no health care access (Baker et al., 2001; Dow et al., 2010; Willson, 2009). Residents commented on learning proper nutrition, how to cook healthy foods, how to protect against disease and being offered the opportunity to improve cardiovascular fitness and strength training. In addition, being in the program allowed the residents to focus more on self-care. Working less gave them more time to consider their own physical, mental, emotional and spiritual needs. All of these factors improved the physical health of the residents, which in turn may have affected the participant's mental health. These findings support the work by Wilson (2009) which found that people in higher SES categories had access to resources that reduced health risks. By being in the Scholar House program, participants, though still in the lower SES category, were afforded resources that were more in line with populations in the higher SES category (Wilson, 2009) such as access to workout facilities, health education and medical clinics. In addition, because the participants were able to work less (again, afforded to the higher SES populations), they had more time to seek health care and take time for self-care.

To answer the third research question, "What relationship does financial empowerment have with HRQoL for Family Scholar House participants?" the researcher examined the final social determinant of health, economic stability.

\section{Economic stability (Financial support)}

Family Scholar House provided financial support via basements stocked with clothing, furniture and food. Residents had monitored access to apartment furniture, clothing for themselves and their children, and food to stock their kitchen when money was limited (usually towards the end of the month). Holidays were also a source of financial support. Local businesses donated free turkeys at Thanksgiving, and sponsored the residents and their children at Christmas. Residents quickly realized that their complete wish list was satisfied and they need not spend any of their own money on gifts for the family.

With the ability to reduce expenditures on rent, food, clothing and holiday items, several of the residents had the opportunity to save money and pay off debt. This provided stress reduction in a variety of ways. First, Scholar House required each resident to save ten dollars per month in a future fund. Family Scholar House held this money until the resident graduated. Knowing that this money would be there at 
graduation gave residents a feeling of security, a "safety net". Family Scholar House also assisted with a home ownership program. Residents could save money towards purchasing a new home and this money was matched (or more) upon graduation. The residents were not as anxious about life after the program, trusting that these funds would cover them as they transitioned out of the Family Scholar House apartments and into a new career and possibly a home of their own. Second, saving money outside of these funds also reduced stress by giving residents the opportunity to purchase larger items with cash. One resident bought her first car, paid fully in cash. Other residents commented on the ability to buy items for their apartment, their children and themselves without having to worry about where the money would come from. Third, residents noted the stress reduction that would normally arise from unexpected bills. Because they had savings, car repairs or medical bills were not as devastating. Fourth, with money saved and debt paid off, residents could use tax returns for something other than bills. In addition, the financial success classes enabled the residents to manage their money, ensuring that bills were paid on time and expenditures were within the monthly budget. All of these factors worked towards alleviating stress caused by limited finances. These findings support research on financial literacy where behavior changes, such as increased savings and decreased debt are seen as positive financial health outcomes (Grimes et al., 2010; NYC Department of Consumer Affairs Office of Financial Empowerment, 2013; Phillips \& Stuhldreher, 2011; Rothwell \& Han, 2010; Willenbrink, 2015).

Because Family Scholar House meets each of the social determinants of health, the resulting improvement of mental health and the health rating score among its residents was expected. Regarding the other three questions of the core four questions on the HRQoL (physically unhealthy days, activity limitations, overall healthy days), the data analysis showed no significant differences between the BRFSS data and the FSH population. Physically, the FSH population was no different from the BRFSS population, and thus no improvements in the physical aspect of the HRQoL were noted. Because the overall healthy days and the activity limitation has a component of physical health as well as mental health, the differences in the mentally healthy days was not enough to cause the combined physical and mental health days to be significantly different from the BRFSS population. In addition, no significant findings were noted with four additional HRQoL questions pertaining to symptoms of poor health. This analysis was done without the 
comparison BRFSS group (as this data is not collected in the same manner among this population) and no significant differences were found among the five sub-groups of the FSH population.

\section{Conclusions}

The Family Scholar House was a unique intervention designed to stop the cycle of poverty by providing college education and support to single parents. The different aspects of the Scholar House program addressed each of the five social determinants of health (economic stability, education, social and community context, health care, and neighborhood and built environment). Results of the studies showed that 0-12 month participant has had significantly more mentally unhealthy days than the BRFSS group; however, this difference was no longer significant at the end of participant's time in the Family Scholar House program. Thus, by the end of their time in the program, the participant's mental health was not significantly different from a comparison population. Qualitative analysis suggested that being in the Family Scholar House program gave participants the opportunity to save money and increase their financial knowledge (banking, credit, budget management, taxes) such that unexpected expenditures were no longer a financial crisis. This opportunity may contribute to the reduced stress levels noted by the participants and thus the improved mental health seen in the quantitative analysis. This study added to the current literature regarding social determinants of health, finding improvement in health in a setting where each of the social determinants are addressed.

\section{Preliminary recommendations for implementation}

These findings are suggestive of several strategies for the design of future interventions aimed at improving the health of people living in poverty situations. Primarily, programs designed to alleviate poverty may benefit from consideration of the social determinants of health, ensuring each component is met. In the Family Scholar House program, while stable housing and education were the focus, intentional implementation of other program components assured all social determinants of health were addressed. However, due to the scope of this study, the researcher cannot infer the results outside of the Scholar House population. Thus, conducting future research on populations in poverty is needed. Locally, in Louisville, work with homeless populations may benefit from consideration of utilizing the Family Scholar House design. For instance, at the Louisville Rescue Mission, men with addictions who come from unstable housing are offered a 9-12 month rehabilitation program to assist with a successful transition into society. 
This program is still evolving, but currently, the men are provided stable housing (neighborhood and built environment), access to medical professionals and workout facilities (health care), a supportive community of church members, staff and fellow addicts all working towards an improved quality of life (social and community context) and their basic financial needs such as food, clothing, laundry and internet met (economic stability). However, one noted determinant, education, is lacking. Because of this, several of the men without a higher education degree struggle to find work that pays more than minimum wage.

Therefore, even if they are working full time and can manage their finances, the lack of income can create a downward spiral leading back to homelessness, addiction and poor health outcomes (Mission, 2014).

\section{Recommendations for improving research}

To improve the quality of this research, responses from all six sub-samples of the Family Scholar House population are needed. In the current study, only two pre-residential participants responded to the online survey and thus were not included in the data analysis. This sub-sample would have provided a baseline of health prior to entering the program and could have been used as a comparison group as well. Use of the Family Scholar House Facebook page might yield greater responses as would incentives provided either by the researcher or by the Scholar House administration. Participants can earn credits towards an apartment. If taking the survey earned them a credit, pre-residents may be more inclined to participate in the survey. The Family Scholar House was very receptive to this study and helpful in organizing the focus groups, providing the space and childcare. More discussion with the administration on ideas to create a higher response rate among the pre-residents may be effective.

The HRQoL survey instrument utilized in this study had been shown to be valid and reliable in determining health-related quality of life. However, this study showed that a survey instrument examining mental health, stress levels and social support might be better suited to understanding the relationship between the social determinants and mental health.

Finally, much of the financial empowerment discussion came from the focus groups. With the online survey, participants rated the financial success component of Family Scholar House low when compared to housing and education. However, in the discussion groups, participants commonly cited financial success and financial empowerment as areas of support and correlated this with mental health improvements. The original financial success program came from the National Center for Family Literacy 
(NCFL) and the National Endowment for Financial Education (NEFE). NEFE has its own survey instrument to gage improvement in financial literacy and financial behaviors. Utilization of this instrument may prove to be a more effective way to measure the role of financial empowerment and its relationship to health.

\section{Recommendations for future research}

The need exists for conducting future studies designed to explore the different interventions utilized by community programs that serve various populations in poverty with known health disparities. The Louisville Rescue Mission and Housing First would be two distinct groups to study, as would St. Vincent DePaul, Wayside Mission and the YMCA Safe Place. These local organizations were developed to alleviate poverty and improve health outcomes through a variety of different interventions, yet only recently has financial empowerment been a consideration in the social services field. Having a better understanding of the relationship with financial empowerment, the social determinants of health and health outcomes may prove to serve as a guide for future interventions designed to work with populations in poverty. Also with evaluation and subsequent focused interventions designed for these various programs, the role of sustainability needs consideration. The Family Scholar House program is well supported through private and public donations, however many community programs lack this sustainability. Thus future intervention design should have a sustainability component.

In addition, an unexpected theme arose from the discussion groups, that of improved well-being of the children within the program. This potential finding leads to questions focused on support for single parents and the resulting improvements that may be seen in the children. The majority of the women commented on the improvement in their children's lives since being in Family Scholar House. Several women commented that this improvement is what kept them in the program. With over 66,000 homeless children living in the state of Kentucky (Research, 2015)and over 7,600 children in Kentucky's foster care system (AdoptUSKids, 2015), could these numbers be significantly reduced if single parents had a network of support available that was designed to alleviate poverty by addressing all the social determinants of health? Such networks of support exist in low-income neighborhoods where community development industries work to improve conditions related to $\mathrm{SDOH}$, but research into health related outcomes is scarce 
(Jutte, Miller, \& Erickson, 2014). It would be worthwhile for future studies in this field to study child wellbeing from this vantage point.

Finally, while improvements in mental health were found in participants who were in the Family Scholar House program, there currently is no way to track how these participants do after leaving the program. Tracking long-term progress is essential in determining if the program truly does break the cycle of poverty. 


\section{REFERENCES}

Adler, N. E., Boyce, T., Chesney, M. A., Cohen, S., Folkman, S., Kahn, R. L., \& Syme, S. L. (1994). Socioeconomic Status and Health: The Challenge of the Gradient. American Psychologist, 49(1), 15-24.

AdoptUSKids. (2015). Kentucky Foster Care and Adoption Guidelines.

Amuedo-Dorantes, C., \& Pozo, S. (2005). On the Use of Differing Money Transmission Methods by Mexican Immigrants1. International Migration Review, 39(3), 554-576. doi: 10.1111/j.1747-7379.2005.tb00280.x

Andresen, E., Catlin, T., Wyrich, K. W., \& Jackson-Thompson, J. (2003). Retest reliability of surveillance questions on health related quality of life (Abstract). Journal of Epidemilogy Community Health, 57(5), 339-343.

Backlund, E., Rowe, G., Lynch, J., Wolfson, M., Kahn, R. L., \& Sorlie, P. D. (2007). Income inequality and mortality: a multilevel prospective study of 521248 individuals in 50 US states. International Journal of Epidemiology, 36(3), 590-590.

Backlund, E., Sorlie, P. D., \& Johnson, N. L. (1996). The Shapre of the Relationship between Income and Mortality in the United States. AEP, 6(1), 12-20.

Baker, D. W., Sudano, J. J., Albert, J. M., Borawski, E. A., \& Dor, A. (2001). Lack of Health Insurance and Decline In Overall Health In Late Middle Age. The New England Journal of Medicine, 345(15), 1106-1112.

Barros, A. J. D., Ronsmans, C., Axelson, H., Loaiza, E., Bertoldi, A. D., França, G. V. A., . . Victora, C. G. (2012). Equity in maternal, newborn, and child health interventions in Countdown to 2015: a retrospective review of survey data from 54 countries. The Lancet, 379(9822), 1225-1233. doi: http://dx.doi.org/10.1016/S0140-6736(12)60113-5

Baruch, Y. (2008). Survey response rate levels and trends in organizational research. Human relations, 61(8), 1139-1160. doi: 10.1177/0018726708094863

Bayer, P. J., Bernheim, B. D., \& Scholz, J. K. (2009). THE EFFECTS OF FINANCIAL EDUCATION IN THE WORKPLACE: EVIDENCE FROM A SURVEY OF EMPLOYERS. Economic Inquiry, 47(4), 605-624. doi: 10.1111/j.1465-7295.2008.00156.x

Bernheim, B. D., \& Garrett, D. M. (2003). The effects of financial education in the workplace: evidence from a survey of households. Journal of Public Economics, 87(7-8), 1487-1519. doi: http://dx.doi.org/10.1016/S0047-2727(01)00184-0

Bernheim, B. D., Garrett, D. M., \& Maki, D. M. (2001). Education and saving:: The long-term effects of high school financial curriculum mandates. Journal of Public Economics, 80(3), 435-465. doi: http://dx.doi.org/10.1016/S0047-2727(00)00120-1

Bradley, E. H., Curry, L. A., \& Devers, K. J. (2007). Qualitative Data Analysis for Health Services Research: Developing Taxonomy, Themes, and Theory. Health Services Research, 42(4), 1758-1772.

Brooks, J., \& Wiedrich, K. (2012). Assets \& Opportunity Scoreboard: A Portrait of Financial Insecurity and Policies to Rebuild Prosperity in America: Corporation for Enterprise Development.

Cairney, J. P. D., Boyle, M. P. D., Offord, D. M. D., \& Racine, Y. M. A. (2003). Stress, social support and depression in single and married mothers. Social Psychiatry and Psychiatric Epidemiology, 38(8), 442-449. doi: 10.1007/s00127-003-0661-0 
Centers for Disease Control and Prevention. (2000). Measuring Healthy Days. Atlanta, GA:

Department of Health and Human Services Retrieved from

http://www.cdc.gov/hrqol/pdfs/mhd.pdf.

Centers for Disease Control and Prevention. (2010). Establishing a holistic framework to reduce inequities in HIV, viral hepatitis, STDs, and tuberclulosis in the United States (V. H. National Center for HIV/AIDS, STD, and TB Prevention, Trans.).

Centers for Disease Control and Prevention. (2014a). Healthy People 2020. Retrieved from http://www.healthypeople.gov/2020/topicsobjectives2020/overview.aspx?topicid=39.

Centers for Disease Control and Prevention. (2014b). National Health Interview Survey. Retrieved April 11, 2014, from http://www.cdc.gov/nchs/nhis.htm

Centers for Disease Control and Prevention. (2014c). Social Determinants of Health. Retrieved April 72014, from http://www.cdc.gov/socialdeterminants/Definitions.htmlhttp://www.cdc.gov/socialdet erminants/Definitions.html

Centers for Medicare \& Medicaid. (2014). Affordable Care Act. Retrieved November 16, 2014, from http://medicaid.gov/affordablecareact/affordable-care-act.html

Chevalier, A., \& Feinstein, L. (2006). Sheepskin or Prozac: The Causal Effect of Education on Mental Health.

Chisolm, T., Johnson, C., Danhauer, J., Portz, L., Abrams, H., Lesner, S., ... Newman, C. (2007). A Systematic Review of Health-Related Quality of Life and Hearing Aids: Final Report of the American Academ of Audiology Task Force on the Benefits of Amplification in Adults. Journal of the American Academy of Audiology, 18(2), 151-183.

Cho, S. H., Gutter, M., Kim, J., \& Mauldin, T. (2012). The Effect of Socialization and Information Source on Financial Management Behaviors among Low- and Moderate-Income Adults. Family and Consumer Sciences Research Journal, 40(4), 417-430. doi: 10.1111/j.15523934.2012.02120.x

City of Louisville. (2014). Cities for Financial Empowerment Coalition. Retrieved March 14, 2014, 2014, from http://louisvilleky.gov/government/community-services/communityfinancial-empowerment-certification

Clark, R. L., Morrill, M. S., \& Allen, S. G. (2012). The Role of Financial Literacy in Determining Retirment Plans. Economic Inquiry, 50(4), 851-866. doi: 10.1111/j.14657295.2011.00390.x

Cole, S., \& Shastry, G. K. (2008). If you are so smart, why aren't you rich? The effects of education, financial literacy and cognitive ability on financial market participation. Cambridge, MA.

Collins, J. M., \& O'Rourke, C. M. (2010). Financial Education and Counseling-Still Holding Promise. Journal of Consumer Affairs, 44(3), 483-498. doi: 10.1111/j.17456606.2010.01179.x

Commonwealth of Kentucky. (2014). Behavioral Risk Factor Surveillance Stystem (BRFSS). Retrieved October 17, 2014, from http://chfs.ky.gov/dph/info/dpqi/cd/brfss.htm Creswell. (2006). Understanding Mixed Methods Research. Thousand Oaks, CA: Sage Publishing. Cruse, M. (2015). Women 4 women.

Danes, S. (2012). NEFE High School Financial Planning Program 2007 Curriculum Evaluation. de Castro, A. B., Gee, G. C., \& Takeuchi, D. T. (2010). Examining Alternative Measures of Social Disadvantage Among Asian Americans: The Revelance of Economic Opportunity, Subjective Social Status, and Financial Strain for Health. J Immigrant Minority Health, 12, 659-671. doi: 10.1007/s10903-9258-3 
Dow, W. H., Schoeni, R. F., Adler, N. E., \& Stewart, J. (2010). Evaluating the evidence base: Policies and interventions to address socioeconomic status gradients in healtha. Annals of the New York Academy of Sciences, 1186(1), 240-251. doi: 10.1111/j.17496632.2009.05386.x

Evans, G. (2003). The built environment and mental health. Journal of urban health, 80(4), 536555.

Family Scholar House. (2014). Family Scholar House. Retrieved July 10, 2014, from http://familyscholarhouse.org/

Farlex. (2014). Segen's Medical Dictionary. Retrieved Nov. 1, 2014, from http://medicaldictionary.thefreedictionary.com/socioeconomic+status

Faul, F., Erdfelder, E., Lang, A.-G., \& Buchner, A. (2004). G*Power 3: A flexible statistical power analysis program for the social, behaviora, and biomedical sciences. Behavior Research Methods, 39, 175-191.

Fox, J., Bartholomae, S., \& Lee, J. (2005). Building the case for financial education. Journal of Consumer Affairs, 39(1), 195-214. doi: 10.1111/j.1745-6606.2005.00009.x

Gale, W. G., Harris, B. H., \& Levine, R. (2012). Raising Household Saving: Does Financial Education Work? Social Security Bulletin, 72(2), 39.

Gallo, L., \& Matthews, K. A. (2003). Understanding the Association Between Socioeconomic Status and Physical Health: Do Negative Emotions Play a Role? Psychological Bulletin, 129(1), 10-51. doi: 10.1037>0033-2909.129.1.10

Goldschmidt, P. (1986). Information Synthesis: A Practical Guide. Health Services Research, 21, 215-236.

Gornick, M. (2002). Disparities in Health Care: Methods for Studying the Effects of Race, Ethnicity, and SES on Access, Use, and Quality of health care: Institue of Medicine.

Gould, E., \& Wething, H. (2012). U.S. poverty rates higher, saftey net weaker than peer countries. Retrieved March 27, 2015, from http://www.epi.org/publication/ib339-us-povertyhigher-safety-net-weaker/

Grimes, P. W., Rogers, K. E., \& Smith, R. C. (2010). High School Economic Education and Access to Financial Services. Journal of Consumer Affairs, 44(2), 317-335. doi: 10.1111/j.17456606.2010.01171.x

Grinstein-Weiss, M., Lee, J. S., Greeson, J. K. P., Han, C. K., Yeo, Y., \& Irish, K. (2008). Fostering low-income homeownership through Individual Development Accounts: A longitudinal, randomized experiment. Housing Policy Debate, 19, 711-739.

Guggenheim, D. (Writer). (2010). Waiting for "Superman". In L. Chilcott (Producer).

Hashima, P., \& Amato, P. (1994). Poverty, Social Support, and Parental Behavior. Child Development, 65(2), 394-403.

Hawkins, R., \& Kim, E. (2012). The Socio-Economic Empowerment Assessment: Addressing Poverty and Economic Distress in Clients. Clinical Social Work Journal, 40(2), 194-202. doi: 10.1007/s10615-011-0335-4

Hogarth, J. M. (2006). Financial Education and Economic Development. Federal Reserve Board. Howell, D. (2013). Statistical Methods for Psychology (Vol. 3rd). Wadsworth: Cengage Learning. Jappelli, T. (2010). Economic Literacy: An International Comparison*. The Economic Journal, 120(548), F429-F451. doi: 10.1111/j.1468-0297.2010.02397.x

Jutte, D. P., Miller, J. L., \& Erickson, D. J. (2014). Neighborhood Adversity, Child Health, and the Role for Community Development. Pediatrics, 135, 548-557.

Kerrick, S., Alzate, I. O., Hunt, K., Marciszko, M., \& Saylor, J. (2011). Women 4 Women; Finace 4 Her. Louisville, KY: University of Louisville. 
Kim, J., \& Richardson, V. (2012). The Impact of Socioeconomic Inequalities and Lack of Health Insurance on Physical Functioning Among Middle-aged and Older Adults in the United States. Health \& Social Care in the Community, 20(1), 42-51.

LaMontagne, C. (2014). Medical Bankruptcy accounts for majority of personal bankruptcies. Retrieved March 30, 2015, from http://www.nerdwallet.com/blog/health/2014/03/26/medical-bankruptcy/

Lentz, T. (2013). Money Talks: Louisville Metro Community Services and Revitalization.

Letkiewicz, J. C., \& Fox, J. J. (2014). Conscientiousness, Financial Literacy, and Asset Accumulation of Young Adults. Journal of Consumer Affairs, 48(2), 274-300. doi: 10.1111/joca.12040

Levine Coley, R., \& McPherran Lombardi, C. (2014). Low-Income Women's Employment Experiences and Their Financial, Personal, and Family Well-Being. Journal of Family Psychology, 28(1), 88-97.

Lowery, A. (2014, March 16, 2014). Income Gap, Meet the Longevity Gap, The New York Times, p. BU1. Retrieved from http://www.nytimes.com/2014/03/16/business/income-gap-meetthe-longevity-gap.html? $r=0$

Lusardi, A., \& Mitchell, O. S. (2008). Planning and Financial Literacy: How Do Women Fare? American Economic Review, 98(2), 413-417. doi: 10.1257/aer.98.2.413

Lusardi, A., Mitchell, O. S., \& Curto, V. (2010). Financial Literacy among the Young. Journal of Consumer Affairs, 44(2), 358-380. doi: 10.1111/j.1745-6606.2010.01173.x

Lynch, J. W., DaveySmith, G., Harper, S., \& Hillemeier, M. (2004). Is Income Inequality a Determinant of Population Health? Part 2. U.S. National and Regional Trends in Income Inequality and Age- and Cause-Specific Mortality. Milbank Quarterly, 82(2), 355-400. doi: 10.1111/j.0887-378X.2004.00312.x

Lynch, J. W., Harper, S., Kaplan, G. A., \& DaveySmith, G. (2005). Associations Between Income Inequality and Mortality Among US States: The Importance of Time Period and Source of Income Data. American Journal of Public Health, 95(8), 1424-1430. doi: 10.2105/AJPH.2004.048439

Lynch, J. W., Smith, G. D., Harper, S. A. M., Hillemeier, M., Ross, N., Kaplan, G. A., \& Wolfson, M. (2004). Is Income Inequality a Determinant of Population Health? Part 1. A Systematic Review. Milbank Quarterly, 82(1), 5-99. doi: 10.1111/j.0887-378X.2004.00302.x

Lynch, J. W., Smith, G. D., Kaplan, G. A., \& House, J. S. (2000). Income Inequality and Mortality: Importance to Health of Individual Income, Psychosocial Environment, or Material Conditions. BMJ: British Medical Journal, 320(7243), 1200-1204. doi: 10.2307/25187854

Miller, W., Richardson Vigdor, E., \& Manning, W. G. (2004). Covering The Uninsured: What Is It Worth? Health Affairs, 23, 157-167.

Mission, L. R. (2014). Homelessness destroys lives.

Moriarity, D. G., Zach, M., \& Kobau, R. (2003). The Centers for Disease Control and Prevention's Healthy Days Measure -- Population tracking of perceived physical and mental health over time. Atlanta, GA: Centers for Disease Control and Prevention.

Moriarty, D., \& Zach, M. (1999). Validation of the Centers for Disease Control and Prevention's Healthy Days measures (abstract). Quality of Life Research, 8(7), 617.

Myers, H. (2009). Ethnicity and socio-economic status-related stresses in context: an integrative review and conceptual model. Journal of Behavioral Medicine, 32, 9-19. doi: 10.1007/s10865-008-9181-4

Nesbitt, L., Harris, M., Hall, C., \& Pallam, H. (2012). Louisville Metro Health Status Report (L. M. D. o. P. H. a. Wellness, Trans.). 
Nobles, J., Ritterman Weintraub, M., \& Adler, N. E. (2013). Subjective socieconomic status and health: Relationships reconsidered. Social Science \& Medicine, 82, 58-66.

NYC Department of Consumer Affairs Office of Financial Empowerment. (2013). NYC Department of Consumer Affairs Office of Financial Empowerment: Progress Report, 2010-2013 (O. o. F. Empowerment, Trans.).

Olstad, R., Sexton, H., \& Søgaard, A. J. (2001). The Finnmark Study. A prospective population study of the social support buffer hypothesis, specific stressors and mental distress. Social Psychiatry and Psychiatric Epidemiology, 36(12), 582-589. doi: 10.1007/s127-0018197-0

Oyserman, D., Bybee, D., Mowbray, C., \& Kahng, S. K. (2004). Parenting self-constructs of mothers with a serious mental illness: efficacy, burden and personal growth. J. Appl. Soc. Psychol, 34, 2503-2523.

Pallant, J. (2005). SPSS Survival Manual. Chicago, IL: McGraw-Hill.

Phillips, L., \& Stuhldreher, A. (2011). Building Better Bank Ons: New America Foundation.

Pickett, K., \& Wilkinson, R. (2007). Child wellbeing and income inequality in rich societies: ecological cross sectional study. BMJ, 1-7. doi: 10.1136/bmj.39377.580162.55

Pickett, K., \& Wilkinson, R. (2015). Income inequality and health: A causal review. Social Science \& Medicine, 128, 316-326.

Research, N. C. o. F. H. a. A. I. f. (2015). America's Youngest Outcasts.

Rhine, S. L. W., \& Greene, W. H. (2006). The Determinants of Being Unbanked for U.S. Immigrants. Journal of Consumer Affairs, 40(1), 21-40. doi: 10.1111/j.17456606.2006.00044.x

Richards, K. V., \& Thyer, B. A. (2011). Does Individual Development Account Participation Help the Poor? A Review. Research on Social Work Practice, 21(3), 348-362. doi: $10.1177 / 1049731510395609$

Roberts, C. M. (2010). The Dissertation Journey. Thousand Oaks, CA: Corwin A Sage Company.

Rothwell, D. W., \& Han, C.-K. (2010). Exploring the Relationship Between Assets and Family Stress Among Low-Income Families. Family Relations, 59(4), 396-407. doi: 10.1111/j.1741-3729.2010.00611.x

Sanmartin, C., Ross, N. A., Tremblay, S., Wolfson, M., Dunn, J. R., \& Lynch, J. (2003). Labour Market Income Inequality and Mortality in North American Metropolitan Areas. Journal of Epidemiology and Community Health (1979-), 57(10), 792-797. doi: $10.2307 / 25570173$

Schinasi, G. (2004). Defining Financial Stability. Retrieved from http://www.imf.org/external/pubs/ft/wp/2004/wp04187.pdf

Schwartz, M. C., Bybee, D., Spang, J., Rueda-Reidl, A., \& Oyserman, D. (2000). Mothers with mental illness: stressors and resources parenting and living. Fam. Soc, 81, 118-129.

SF Office of Financial Empowerment. (2014). Bank on San Francisco. from http://sfofe.org/programs/bank-on

Sherraden, M., Laux, S., \& Kaufman, C. (2007). Financial Education for Social Workers. Journal of Community Practice, 15(3), 9-36.

SPSS. (2014). Chicago, IL.

Sweet, E., Nandi, A., Adam, E., \& McDade, T. (2013). The high price of debt: Household financial debt and its impact on mental and physical health. Social Science \& Medicine, 91, 94-100.

The Kaiser Commission on Medicaid and the Unisured. (2014). The Uninsured, the Affordable Care Act, and Kentucky. In K. F. Foundation (Ed.).

The White House. (2014). Poverty. Retrieved October 6, 2014, 2014, from http://www.whitehouse.gov/issues/poverty/ 
Thomas, D. R. (2006). A General Inductive Approach for Analyzing Qualitative Evaluation Data. American Journal of Evaluation, 27(2), 237.

Thomas, S. (2012). On Numbers. Retrieved February 16, 2014 http://www.bizjournals.com/bizjournals/on-numbers/scottthomas/2012/02/mississippi-and-texasdominate.html?appSession=881310733781090\&RecordID=\&PagelD=2\&PrevPageID=1\& cpipage $=2 \&$ CPISortType $=\&$ CPlorderBy $=$

Thomas, S. B., \& Quinn, S. C. (2008). Poverty and Elimination of Urban Health Disparities. Annals of the New York Academy of Sciences, 1136(1), 111-125. doi: 10.1196/annals.1425.018

Tischler, V., Rademeyer, A., \& Vostanis, P. (2007). Mothers experiencing homelessness: mental health, support and social care needs. Health \& Social Care in the Community, 15(3), 246-253. doi: 10.1111/j.1365-2524.2006.00678.x

U.S. Census Bureau. (2014). Data Collection and Capture for Housing Units. Retrieved from http://www.census.gov/acs/www/Downloads/survey methodology/acs design metho dology ch07 2014.pdf.

U.S. Department of Health \& Human Services. (2014a). 2014 HSS Poverty Guidelines. Retrieved March 14, 2014, 2014, from http://aspe.hhs.gov/poverty/12poverty.shtml\#guidelines

U.S. Department of Health \& Human Services. (2014b). Health-related quality of life and wellbeing. Retrieved July 10, 2014, from http://www.healthypeople.gov/2020/topicsobjectives2020/overview.aspx?topicid=19

United States Census Bureau. (2012). Income, Poverty and Health Insurance Coverage in the United States: 2012 (2012 ed.). Washington D.C.: Economics and Statistics Administration.

United States Department of Agriculture. (2012). Effects of the Special Supplemental Nutrition Program for Women, Infants, and Children (WIC): A Review of Recent Research.

United States Department of Agriculture. (2014). Supplemental Nutrition Assistance Program (SNAP). Retrieved October 10, 2014, from http://www.ers.usda.gov/topics/foodnutrition-assistance/supplemental-nutrition-assistance-program-(snap).aspx

van Rooij, M. C. J., Lusardi, A., \& Alessie, R. J. M. (2012). Financial Literacy, Retirement Planning and Household Wealth*. The Economic Journal, 122(560), 449-478. doi: 10.1111/j.14680297.2012.02501.x

Waddell, M. (2015). Financial literacy.

Wang, L. (2002). Determinants of Child Mortality in Low-Income Countries: Empirical Findings from Demographic and Health Surveys: The World Bank.

Wilkinson, R. G., \& Pickett, K. (2007). The problems of relative derivation: why some societies do better than others. Social Science \& Medicine, 65, 1965-1978.

Wilkinson, R. G., \& Pickett, K. (2008). Income inequality and socioeconomic gradients in mortality. American Journal of Public Health, 98, 699-704.

Wilkinson, R. G., \& Pickett, K. (2009). Income inequality and social dysfunction. Annual Review of Sociology, 35(493-512).

Wilkinson, R. G., \& Pickett, K. E. (2006). Income inequality and population health: A review and explanation of the evidence. Social Science \& Medicine, 62(7), 1768-1784. doi: http://dx.doi.org/10.1016/j.socscimed.2005.08.036

Willenbrink, C. (2015). Bank On Louisville.

Willson, A. E. (2009). 'Fundamental Causes' of Health Disparities: A Comparative Analysis of Canada and the United States. International Sociology, 24(1), 93-113. doi:

$10.1177 / 0268580908099155$ 
Wilson, A. E. (2009). 'Fundamental Causes' of Health Disparities: A Comparative Analysis of Canada and the United States. International Sociology, 24(1), 93-113. doi: $10.1177 / 0268580908099155$

World Health Organization. (2008). Commission on Social Determinants of Health (CSDH), Closing the gap in a generation: health equity through action on the social determinants of health Final report of the Commission on Social Determinants of Health. 


\section{CURRICULUM VITAE}

\section{Chelsey Franz PhD., ATC}

12312 Crosswinds Dr. Louisville, KY 40243 (503)910.7513 cfranz@bellarmine.edu

\section{Career Objectives:}

To work with impoverished communities in poverty and health disparity reduction.

Education:

- Doctorate in Public Health Sciences, University of Louisville, Louisville, Kentucky

- Master of Science in Health \& Human Performance/Exercise Science; emphasis Sports Medicine, Oregon State University, Corvallis, Oregon, 2004

- Bachelor of Science in Physical Education; emphasis Athletic Training, Western Oregon University, Monmouth, Oregon, 1998

Employment History:

- August 2014 to present - Faculty Bellarmine University, Louisville, Kentucky

- October 2012 to June 2014 - Wounded Warrior Battalion, Ft. Knox, Kentucky

- Athletic Trainer hired through University of Louisville to work with the WWB

- January 2013 to August 2014 - Part-time Instructor University of Louisville, Louisville, Kentucky

- July 2008 to December 2010 - Athletic Training Program Director, TAI Valley Physical Therapy, Keizer, Oregon

Career Achievements:

- Member of the Honorable Order of the Kentucky Colonels; presented March 2013, for my work with the Wounded Warriors

- Athletic Training Program Director for Salem-Keizer School District - Managed a group of 10 Athletic Trainers covering 6 high schools in the state's second largest school district. Developed and implemented several new programs to benefit the health and wellness of high school student athletes. In charge of all aspects of the program, ranging from budgeting to marketing to HR related tasks.

- Served on Oregon Concussion and Awareness Management Program; served on Salem-Keizer School District Concussion Management Board

- PEO (Philanthropic Education Organization) Member; October 2013

Publications:

Franz, C.E. (2014). Financial empowerment in mid to low income individuals. $4^{\text {th }}$ Annual Dialogue on

Diversity Conference. Presentation given at University of Louisville in Louisville, KY (peer reviewed).

Loprinzi, P.D., Franz, C., \& Hager, K.K. (2013). Accelerometer-assessed physical activity and depression among U.S. adults with diabetes. Mental Health and Physical Activity.

Interests:

Spending time with my husband and two daughters. Mission trips to developing countries; working with populations in poverty. Educating and assisting individuals and groups on life goals. All forms of exercise. 